Chapman University

Chapman University Digital Commons

English (MA) Theses

Dissertations and Theses

Spring 5-17-2019

\title{
The Efficacy of Varying Small Group Workshops in the Composition Classroom
}

\author{
Daniel Strasberger \\ Chapman University, strasberger@chapman.edu
}

Follow this and additional works at: https://digitalcommons.chapman.edu/english_theses

Part of the Educational Methods Commons, Higher Education and Teaching Commons, and the Language and Literacy Education Commons

\section{Recommended Citation}

Strasberger, Daniel. The Efficacy of Varying Small Group Workshops in the Composition Classroom. 2019. Chapman University, MA Thesis. Chapman University Digital Commons, https://doi.org/10.36837/ chapman.000066

This Thesis is brought to you for free and open access by the Dissertations and Theses at Chapman University Digital Commons. It has been accepted for inclusion in English (MA) Theses by an authorized administrator of Chapman University Digital Commons. For more information, please contact laughtin@chapman.edu. 
The Efficacy of Varying Small Group Workshops in the Composition Classroom

\author{
A Thesis by \\ Daniel S. Strasberger \\ Chapman University \\ Orange, CA \\ Wilkinson College of Arts, Humanities, and Social Sciences \\ Submitted in partial fulfillment of the requirements for the degree of \\ Master of Arts in English
}

May 2019

Committee in charge:

Ian Barnard, Ph.D., Chair

Morgan Read-Davidson, MA/MFA.

Brian Glaser, Ph.D. 
The thesis of Daniel S. Strasberger is approved.

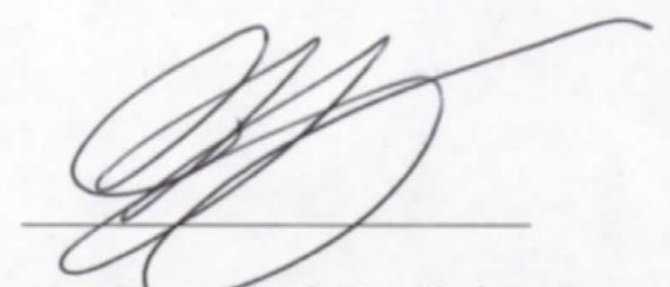
Ian Barnard, Ph.D., Chair

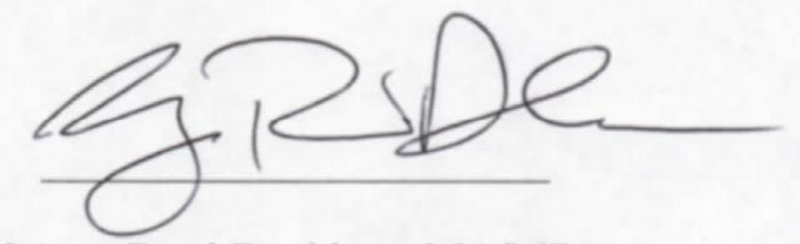

Morgan Read-Davidson, MA/MFA.

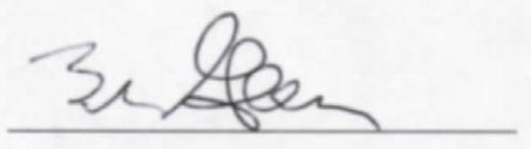

Brian Glaser, Ph.D.

May 2019 
The Efficacy of Varying Small Group Workshops in the Composition Classroom Copyright (C) 2019

by Daniel S. Strasberger 


\section{ACKNOWLEDGEMENTS}

I would like to take a moment to thank my thesis chair Dr. Ian Barnard, alongside the rest of my committee Morgan Reid-Davidson and Dr. Brian Glaser, for all their help and support in the process of writing this. I also thank all my students, not only for their hard work and dedication to my ENG 103: Writing About Writing course, but also their patience with me as I learned about my own teaching process alongside them. 


\begin{abstract}
The Efficacy of Varying Small Group Workshops in the Composition Classroom by Daniel S. Strasberger
\end{abstract}

This I.R.B. approved study takes a look at the efficacy of small group workshops in the composition classroom and whether it is more beneficial for a student to remain in the same small groups between drafts, or whether it is better to change small groups and get a new set of eyes on a new draft. In my first-year English Composition course, ENG 103: Writing About Writing, I take a look at two different assignments, the Personal Narrative and the Research Paper, and how they changed over three drafts. Altering the group workshops for the first and second drafts, I administered surveys to scale how helpful the workshops were. To verify the results, I chose four different sets of essays to look at as case studies and break down how the drafts changed depending on the workshops. In the end, this study attempts to show how altering how small group workshops are run can be beneficial for the writer. 


\section{TABLE OF CONTENTS}

Chapter 1: Introduction 1

1.1 Literature Review 2

$\begin{array}{ll}1.2 \text { Methodology } & 7\end{array}$

Chapter 2: Personal Narrative 11

2.1 Variables 11

2.2 Workshop One: Survey Analysis $\quad 12$

2.3 Workshop Two: Survey Analysis $\quad 15$

2.4 Case Study Alpha: Results $\quad 110$

2.5 Case Study Beta: Results 23

2.6 Case Studies Alpha and Beta: Analysis $\quad 25$

Chapter 3: Research Paper 25

3.1 Variables $\quad 25$

3.2 Workshop One: Survey Analysis 25

3.3 Workshop Two: Survey Analysis 28

3.4 Case Study Alpha: Results $\quad 29$

3.5 Case Study Beta: Results 31

3.6 Case Studies Alpha and Beta: Analysis 33

Chapter 4: Conclusion $\quad 35$

$\begin{array}{ll}\text { Works Cited } & 38\end{array}$

$\begin{array}{ll}\text { Appendices } & 40\end{array}$ 


\section{LIST OF FIGURES}

Figure 1: Ch. 2 Workshop One Survey Feedback

Figure 2: Ch. 2 Workshop Two Survey Feedback: Overall

Figure 3: Ch. 2 Workshop Two Survey Feedback: Absent Students

Figure 4: Ch. 2 Workshop Two Survey Feedback: Same Groups

Figure 5: Ch. 2 Workshop Two Survey Feedback: Different Groups

Figure 6: Ch. 3 Workshop One Survey Feedback

Figure 7: Ch. 3 Workshop Two Survey Feedback 


\section{Chapter 1: Introduction}

In fall of 2018, I designed and taught my first English 103 class: a first-year composition course at Chapman University. Given the flexibility to choose my own pedagogy, I chose 'Writing About Writing,' a composition-based class heavily influenced by Doug Downs and Elizabeth Wardle. Instead of depending a topic that has "nothing to do with writing" to teach about writing, this pedagogy introduces "students directly to what writing researchers have learned about writing and challenging them to respond by writing and doing research of their own" (Downs and Wardle v). It focuses on teaching writers how to approach a reading, choose an argument or topic, write toward the audience, and - most importantly - how to revise and give proper feedback. My goal was to teach students that writing is a skill, a process, not just a one-time action.

I used Writing About Writing: A College Reader, co-edited by Downs and Wardle, as my main text for the course. In designing the syllabus, I assigned three major writing assignments: an Open Letter, a Personal Narrative, and a Research Paper (all of which I will go into detail later). For each of these assignments, I designated two Fridays for small group workshops, where students would break off into smaller groups and give feedback on their peers' drafts one and two, before turning in the third draft to be graded.

A few weeks into the semester, I ran my first set of workshops for my Open Letter. The assignment was to address a letter to a person or group of people specific, taking a stance of a controversial topic, whether it was gun control or vaccinations. My goal was for my students to write to a specific audience, and develop their own voice. When the students broke off into their workshops for the second draft on the second Friday, I noticed that the students remained in the same small groups they were in on the previous week when workshopping their first drafts. This 
brought up the question that I considered but never explored thoroughly: was it beneficial for students to remain in the same small groups while workshopping a piece, or would a different set of eyes help provide a differing and more helpful perspective?

\subsection{Literature Review}

It is important to note that I am just one of many who have stumbled upon this very question. Many academics have written about workshops and process-based pedagogy. Consciously or unconsciously, I use the theories that composition teachers have written about in the past. When I focus on student collaboration, I build onto suggestions from John Trimbur, Muriel Harris, Lisa Ede and Andrea A. Lunsford; when I give authority to the students, I feed off of texts such as "Writing Students Need Coaches, Not Judges" by Lynn Holaday or Writing Without Teachers by Peter Elbow. The goal of this study is not to have some sort of revelation about writing but, instead, to build off of what I and others have learned from the composition classroom.

When designating each assignment with three distinct drafts, I thought of Anne Lamott's essay "Shitty First Drafts" where she recounts her friend's description of drafting. "The first draft is the down draft - you just get it down" explains Lamott (855). "The second draft is the up draft - you fix it up. You try to say what you have to say more accurately. And the third draft is the dental draft, where you check every tooth, to see if it's loose or cramped or decayed, or even, God help us, healthy" (855). Each draft has a different goal to allow the writer a certain freedom. Drafting becomes trial and error, where you are allowed to fail. Lamott describes how after writing a first draft that "[T]here may be something in the very last line of the very last paragraph 
on page six that you just love, that is so beautiful or wild that you now know what you're supposed to be writing about, more or less, or in what direction you might go - but there was no way to get to this without first getting through the first five and a half pages" (854). After creating the first draft, it is important for a writer to be able to identify which part of their own writing is the strongest.

When many students feel apprehensive about their own writing abilities, it is important to promote collaboration within the classroom. In "Workshop Sessions in English Composition" Ralph Bellas argues that putting students into small group workshops helps build their confidence levels as writers. Bellas suggests "that students should be left more to their own resources in trying to increase their writing effectiveness. Shackled to a traditionally structured composition course, students do not have sufficient opportunity to discover for themselves the nature of the writing experience" (273). That is to say, the traditional structure where students change their writing to appease the professor is restrictive because it prevents students from discovering their own style of writing. His suggestion is that small group workshops is one way to combat that stifling structure.

Bellas argues a "student writer in a small group finds it easier to use "his words to describe his experiences," to achieve, as Donald C. Stewart contends, "integrity in his prose" which must be one of the major objectives of any composition course' (273). By allowing students to find their own unique voice, small group workshops help to promote confidence within a writer, and thus encourages them to continue to write (Downs and Wardle; Ede and Lunsford; Harris, Trimbur).

Many instructors, myself included, turn to the "teacherless classroom" concept (Elbow 117), where we as instructors step back to hand the writer authority back to the students. The 
idea is that each student has their own literacy, and the classroom is a place to share, a "Contact Zone" (Pratt 38) where they learn from one another. Kenneth A. Bruffee also an instructor's authority as he argued "By challenging the traditional view of the teacher's authority, collaborative learning helps prepare students for effective interdependence in an increasingly collaborative world" (39).

In the study "Addressing Instructor Ambivalence about Peer Review and SelfAssessment," Pamela Bedore and Brian O'Sullivan surveyed instructors who conducted peer workshops in class to see what happens when students are given the authority as a writer. With students still grappling with their writing, some of the pitfalls of peer workshops identified in this study included "the difficulty for students to take on another person's perspective, the overwhelming nature of material generated by collaborative assessment, its interconnectedness with other portions of the course, and ambiguity about the instructor's role" (Bedor and O'Sullivan 24). Where the difficulty of taking criticism is an important worry, which I explore later on in this section, the role of the instructor is an issue during small group workshops. What do I do while students are in their small groups, workshopping? All I can do, it seems, is walk around, listen in, and play the role of coach, promoting conversation (Holaday).

This question of role is expanded with the looming issue of grading. Bedor and O'Sullivan's study also suggests that "the importance of the grade had the potential to undermine the value students placed on collaborative assessment, since students would pay more attention to instructor feedback than to their own or their peers' critiques" (27). Up until this point, students often worked toward the grade, altering their styles to fit to what would get them the A. When peer workshopping, the worry of the grade still has the possibility of haunting them, causing students to focus on lower-level concerns like grammar and syntax. In my class, the 
portfolio, which I explain in the Methodology section, is my attempt to bridge that gap, giving the students one last chance to edit toward the grade. That, in theory, should allow some room for students to explore rather than just try to get the A.

Convincing students to trust their own abilities is also a key part to a successful workshop (Elbow; Holaday). Charlotte Brammer and Mary Rees explain in "Peer Review from the Students' Perspective: Invaluable or Invalid?" that it is important to emphasize that a workshop is a conversation. They state "Helping students to accept that collaboration rather than correction as the goal of the writing group is essential to the successful peer review session" (81), explaining that it is important to nurture the good habits of conversation, of constructive criticism, rather than telling and criticizing. The article goes on to emphasize '[I]f we value peer review as a critical component of a fully elaborated writing process and accept the social interactive perspective of writing, then we must take the necessary steps to allow students to learn to trust their classmates as "true peers"" (82). The proper time and steps should be taken in every course to show students how to effectively workshop in small groups in order to succeed.

Much like Ede and Lunsford, and Bruffee have argued, Ian Barnard explains in "WholeClass Workshops: Transformation of Students Into Writers" that "[T]eachers cannot expect students to perform effectively in these workshops without adequate training, modeling, and discussion, as the workshops often represent a radical departure from teacher-centered modes of pedagogy to which students are accustomed," (128). To help students have an effective workshop, it is important to set up and model a workshop, showing them what are good and what are bad practices for workshop.

Barnard's article, however, argues for the use of whole-class workshops, opposed to small-group workshops, that "[C]lass members are not addled with a small group that might be 
unproductive or with a few group members with whom they might not get along" (127). With more eyes on a paper, it makes sense that there would be a wider range of feedback, but it does come with a cost. Having whole-class workshops take time, and may prevent some students from getting workshopped. Though Barnard argues that it is the act of workshopping that helps a reader grow as a writer, he is also ignoring the fact that if there is not enough time to workshop every draft of every student, that some students might not get feedback on the draft they feel least confident about.

Small Groups in Writing Workshops: Invitations to a Writer's Life, by Robert Brooke, Ruth Mirtz, and Rick Evans, explain how collaborations between the small groups help students look at writing differently. Small groups, they explain, allows students "to explore their own possibilities for a writer's life through participation in a small community of writers; repeated attention to the effect of their words and topics on other people; reflection on their topics, writing processes, and the responses of their group; and observing the ways in which their group members choose to use writing within the contexts of their diverse lives" (12). By immersing themselves in the writing, conversing in their small groups about the topic and their goals in that specific piece of writing, they engage with their peers and learn from one another, a concept again going back to Bruffee.

In their book, however, they support students remaining in the same small groups between workshops. If students work well with their small groups, they contend that they "tend not to see themselves as 'stuck' in their group, in the same way that they don't feel 'stuck' in their circle of friends or family or teammates or co-workers" (36). This suggests that students feel comfortable with the same set of eyes on their work. With comfort comes respect, and with 
respect, the students will listen to their peers and use what information they share to help improve their work.

Though respect within a small group workshop is a good reason to keep students in the same groups, there is no guarantee that every group will mesh well. Even Brooke, Mirtz, and Evans state that "When students find themselves 'stuck' with people they either don't like, don't agree with, or don't respect, they may withdraw from participating in the group, just as they would withdraw from participating in a group outside of class which alienates them" (36). If students lose respect for the peers in their workshops, any suggestions on the drafts, whether helpful or otherwise, may be dismissed because of the bias of the writer. This brings the focus back onto preparing the students to properly workshop one another, but even that is not a foolproof method of avoiding this issue. This scenario seems to be a perfect reason why to alternate workshop groups between drafts.

\subsection{Methodology}

To understand my workshop methods, it is important to understand my course design. My English 103 course met three times a week (Monday, Wednesday, and Friday) for 50-minute class sessions. Using the textbook Writing About Writing as my guide, I organized the week into three distinct practices: large group discussions on Mondays, small group activities on Wednesdays, and small group workshops on Fridays. I assigned three major writing assignments, an Open Letter, a Personal Narrative, and an Research Paper. The students had two weeks for each assignment, workshopping draft one and draft two on consecutive Fridays, before turning in the third draft on the Sunday of the second week for me to grade. With 18 students, I split the class into six groups of three, and gave them ten minutes to workshop each student's piece in workshop one, fifteen minutes in workshop two. 
Once I obtained I.R.B. approval for the study, my students signed the permission forms to allow me to quote from the various drafts of the designated piece and to quote the surveys they filled out at the end of each workshop. To safeguard their privacy, I will never refer to the students by name.

To ensure proper workshop etiquette, I followed the example of other scholars and held a mock workshop (Barnard; Bruffee; Ede and Lunsford; Harris). I passed around some of my own unpolished writings and instructed the students how to be respectful, yet provide constructive feedback on a piece of writing. I also put more of an emphasis on higher level concerns such as argument, context, and voice, as opposed to lower level concerns like spelling errors and sentence structure.

The workshop structure followed Anne Lamott's descriptions of drafting. For the first workshop, I required at least 300 words of prose. It could be a work in progress, starting at any point of the piece. This was to encourage engagement without requiring a finished piece. For the second draft, I required the students to have an improved, near completed draft. Whether or not the first draft was a completed draft, it was important that the students revise and improve upon their writing through workshop suggestions. To track that changes were made between drafts, I had each student submit each draft online through Blackboard.

After the first workshop where students were allotted ten minutes for each peer workshop, the students were given a survey to fill out (see Appendix One). They rated how helpful the workshop was, highlighting either "Not Helpful”, "A Little Helpful”, "Somewhat Helpful", or "Very Helpful". They were then asked to expand on why the workshops were or were not helpful. 
A week later, I would split the workshops in half. Three of the student groups would stay the same, and three would alternate so no students would workshop the same piece as the past week. After the second workshop, where students were allotted fifteen minutes for each peer workshop, the students were given a second survey (see Appendix Two). They identified whether they were in the same or different workshops, then responded to the same grading scale as the week prior. For the final question they answered why they chose that response and were given an additional prompt about whether this workshop was more or less helpful than their first workshop.

One issue the study faced was the worry that students might not give accurate feedback in their surveys. Whether it can be attributed to writing what they thought I wanted them to say, or not understanding the true worth of the workshop experienced, the surveys should not be taken as facts. Just because a student says the workshop was "Very Helpful" does not mean they got the help they needed, or vise versa. To double-check that their feedback had merit, I took two students from each set of essays and analyzed all three of their drafts to study the differences between workshops.

The final project for the class was a portfolio, where the students compiled all of their drafts together and edited at least one piece of writing a final time. Any piece could be revised for a better grade, provided the students discussed the third draft with me in one-on-one meetings at the end of the semester. This process, emphasized throughout the semester, was my way of combatting the "writing to the teacher" issue. Instead of the student fearing a permanent grade when they turn in their assignment without feedback from the teacher, this allows students to (potentially) trust their own voice and find their own way of writing the piece. The fault with this approach, of course, is that the revisions for said portfolio would be based off my suggestions for 
the grade. My hope would be that after three drafts without my feedback, that the students would gain enough confidence in order to stick with their own voice and style. 


\section{Chapter 2: Personal Narrative}

My personal narrative prompt goes as follows:

Write a personal narrative where a perception has changed. Perception is the way someone thinks or understands a subject, whether it be someone or something. This is developed through past experiences, feelings, and preconceived notions; for example, two people that read the same story or look at the same picture can have two completely different interpretations on the subject.

The essay will be a 500 to1000 word personal narrative explaining an anecdote that changed how the narrator perceived someone or something. Instead of being a play-byplay of what transpired, the paper should engage critically with the anecdote and how the perception was changed through this experience.

\subsection{Variables}

First thing to note, is that my class only represents a small sample size. Eighteen students (at most) is not a large enough number to make any conclusive results. These results are, rather, suggestive and though they can have merit, cannot stand on their own. Instead, it is important for me to use what I learn to influence my teaching practices in the future, without allowing me to settle with any concrete notions.

Also, like anything in life, things did not go completely according to the plan. Absences and underage students (unable to sign the consent forms for Human Research Subjects) presented challenges for my data and analysis.

In the first workshop, two of the 18 students were absent. To alleviate the workshop numbers, and to still provide an adequate number of peer workshoppers, the class was broken up into five groups instead of six, with four groups of three and one group of four.

During the next workshop, both of the students who were absent the previous week showed up, and one who showed up for the first workshop was absent during the second. Students also trickled in late, and with the lack of time during class - groups having to finish three 15-minute peer workshops in the 50-minute class - the shifting of the workshops was 
skewed. The class ended up with three groups of three with different peer editors. One group of three had one student participating in the second workshop with the two students absent for the first workshop. The last two groups remained the same as they were the previous week, with one group of two and one group of three. The biggest issue I also faced with these groups was that three out of the five students were underage when signing the consent forms, which prevents me from directly quoting either their surveys or their drafts.

\subsection{Workshop One: Survey Analysis}

After the first workshop, the survey feedback was mostly positive. Out of the 16 students, seven $(43.75 \%)$ reported the workshop was "Very Helpful", seven (43.75\%) reported it was "Somewhat Helpful", and two (12.5\%) reported it was "A Little Helpful" (examples in Appendix Three).

In Figure 1, you can see 14 out of $16(87.5 \%)$ of the students reporting positive engagement of "Very Helpful/Somewhat Helpful". The only two students who reported the workshops were "A Little Helpful" still reported positive feedback from the workshops while citing issues faced in their own small groups. 


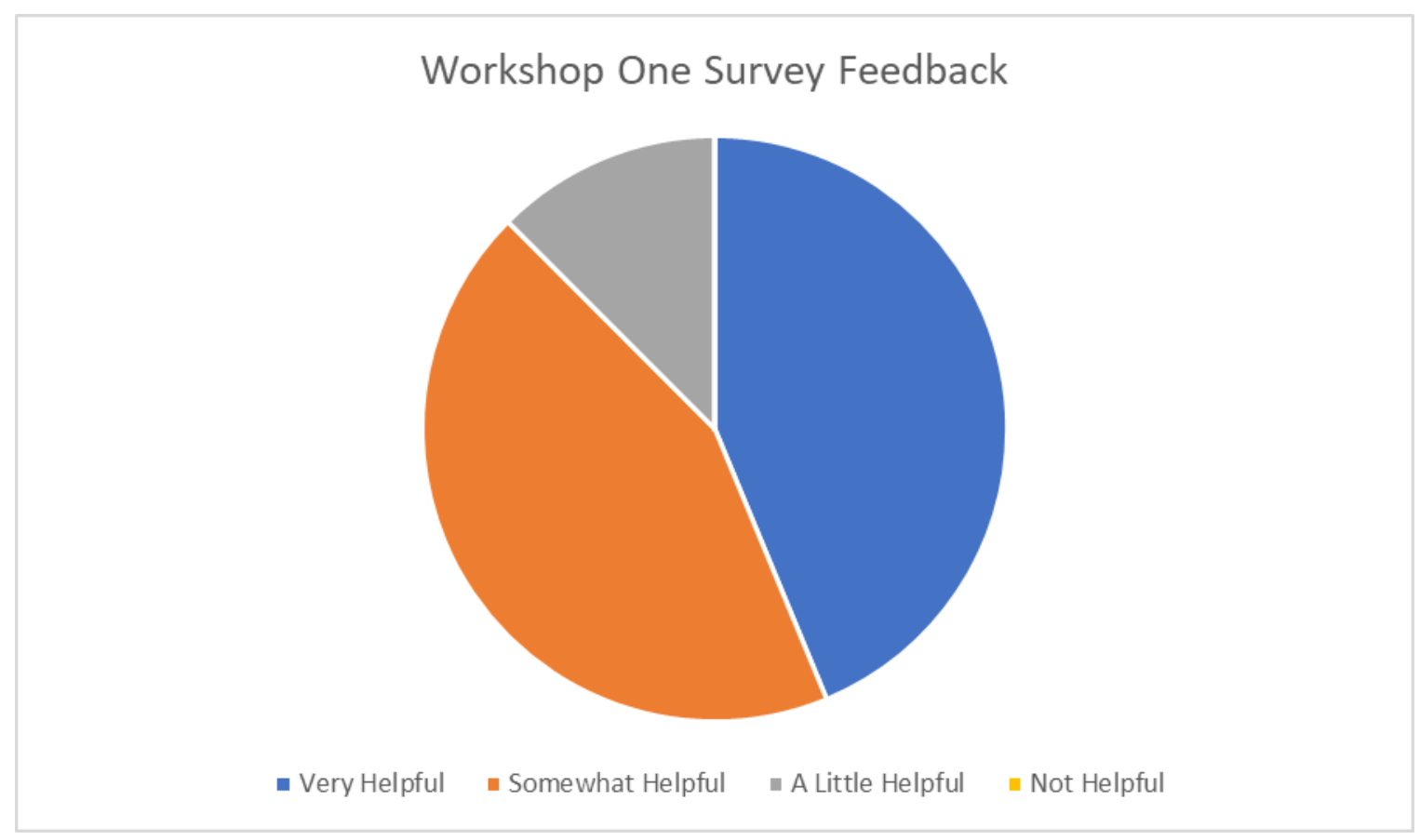

Figure 1: Ch. 2 Workshop One Survey Feedback

In the survey examples for the first workshop, some students noted how beneficial it was

for them to receive feedback early in the drafting process. Not requiring a completed draft on the first workshop, it allowed the students to get suggestions on the path the narrative took, even when still in the process of completion. "It was helpful to hear about what I was doing right. I was unsure if I followed the prompt correctly but everyone agree that I was" explained example A. As Lamott described for first drafts, students can have a lot of self-doubt and this student demonstrates how peer encouragement and suggestions help to give the writer confidence to keep going. At that point, it could be easy to be discouraged, but the small group workshops help to push the writer beyond that and continue with confidence.

Many of the students recognized how the different perspectives in their small group workshops were helpful. The student in example B indicated the workshop was "Very Helpful" and that they found "it very helpful because there is more than one perspective on my work. Everyone has a different approach to their writing therefore getting multiple perspectives is 
essential to making your work better." In this case, the student recognizes that other perspectives would provide them different approaches to their text, which would help them see how readers might interpret the work. The student in example $\mathrm{C}$, who indicated the small group workshop was "Somewhat Helpful", reaffirmed this feeling with "I think that this was helpful because I got to hear other people's perspective on my writing piece. When other people read my piece, they give me opinions that I didn't think about prior to hearing it from them which is useful." The more eyes on a piece, the more feedback the writer can receive, and in turn it, hopefully, would help improve the next draft.

One of the issues indicated in the first set of surveys, however, seemed to come from the first draft requirements. As stated above in Chapter 1 in the methodology section, the requirement for the first draft was a page of writing. The goal was to allow room for growth, and give the students confidence to continue on to the next draft. Because of this flexibility, the variety of types of drafts became a mixed bag. Some students, such as in example C, brought in more completed texts. The student explained how their work was near completion and "they did not have many suggestions for me about how to edit it, but the suggestions they did give me were helpful and I used it in my paper." The student goes on to recognize that "If I have an extremely rough draft then it would be beneficial to me because they would help me form the piece and help give me ideas on how to structure my piece." The place they were at in the piece determined how effective the workshop became.

On the opposite side of the spectrum, many were in the early stages of drafting. Because of the length, the 10 minutes allotted to each workshop varied in effectiveness. In example D the student submitted an early draft, and explained "because our narratives are still so short and incomplete, it was hard to really work on them and make suggestions." Indicating a "Somewhat 
Helpful", this student suggests that if there was a more completed product, that the workshop would have been more beneficial to improving the piece. Likewise, student in example E stated "it was difficult for all of us to use the full 10 minutes to workshop, due to the length of the draft. Because there were many ideas and explanations missing from our first drafts, it was difficult to critique the incomplete work." This student indicated that the workshop was "A Little Helpful", but if the drafts were further to completion, then the workshop would have been more beneficial. Still, this student recognizes that the workshop helped "bounce ideas off of my group members about where I was going with this piece, and have them provide feedback about the overall organization of my work."

\subsection{Workshop Two: Survey Analysis}

The survey feedback for the second set of workshops was similarly successful with positive feedback. Out of the 17 students overall, nine (52.9\%) reported the workshop was "Very Helpful", seven (41.18\%) reported it was "Somewhat Helpful", and one (5.88\%) reported it was "A Little Helpful” (examples in Appendix Four).

Again, as seen in Figure 2, the overall feedback for the second workshop was positive. A higher majority leaned the positive "Very Successful/Somewhat Successful" (94\%) while only one student stated the workshop was "A Little Successful". This suggests that even doing multiple drafts, whether or not you have the same groups, revision is still a useful tool, an idea already supported by Bruffee, Harris, and Trimbur. 


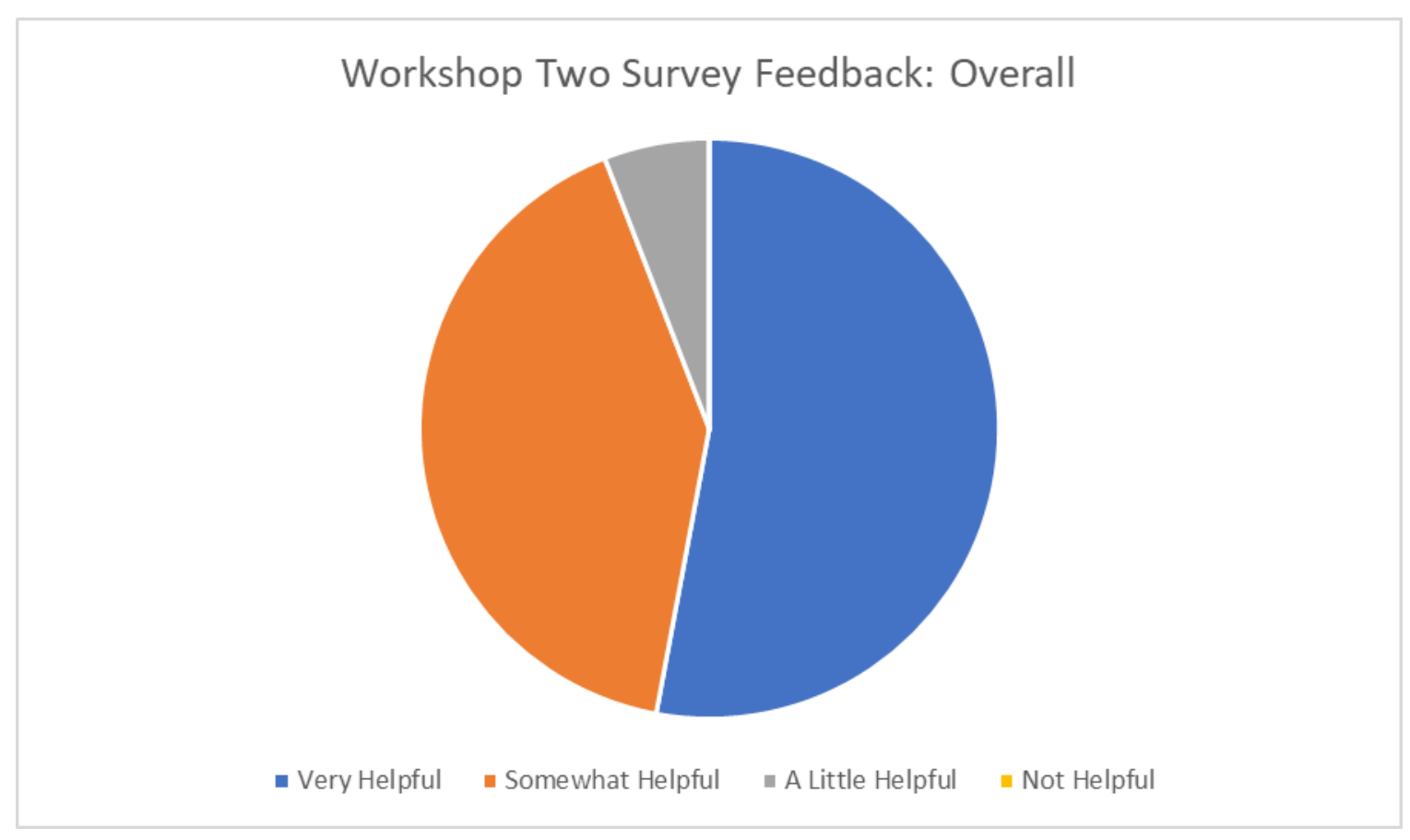

Figure 2: Ch. 2 Workshop Two Survey Feedback: Overall

The variables within the classroom setting changed the way I looked at my study, but also strengthened the reasoning for multiple workshops. The first issue to look at is the students that were absent for the first workshop, but were able to participate in the second workshop. As shown in Figure 3, both students marked the workshop as "Very Helpful" because it was their first workshop on that piece. In the survey examples for the workshop one of these students in example F explained "My peers gave me some good advice on what I should do for my third draft, I am feeling confident that my third draft will be great." Even though this workshop was later in the drafting process, students reported it still helped to provide useful feedback. 


\section{Workshop Two Survey Feedback: Absent Students}

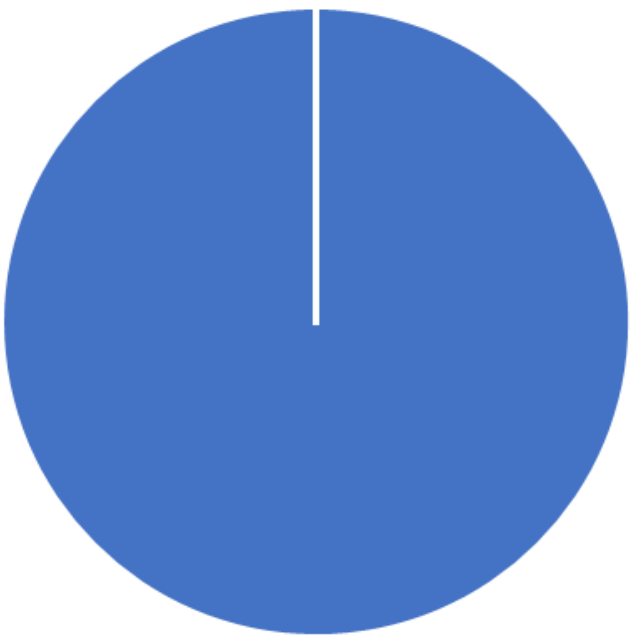

- Very Helpful $\quad$ Somewhat Helpful $\quad$ A Little Helpful $\quad$ Not Helpful

Figure 3: Ch. 2 Workshop Two Survey Feedback: Absent Students

The students who remained in the same small group workshops reported positive

feedback, yet were the only group that had the majority as "Somewhat Helpful" (three out of five or $60 \%$ of the students) instead of "Very Helpful" (two out of five or $40 \%$ of students), all shown in Figure 4. Though a smaller pool to draw from, it was interesting to note that it was not as "successful" as the other scenarios. In example G, the student appreciated the same eyes on their paper. "I saw what I was still missing and got advice on how to incorporate it into my narrative since my partners were able to get a sense of the whole story." From this explanation it could be argued that the same set of eyes, the small group knowing what the student's goal is, was what benefited this student. However, this could also have been achieved with a different small group workshop. 


\section{Workshop Two Survey Feedback: Same Groups}

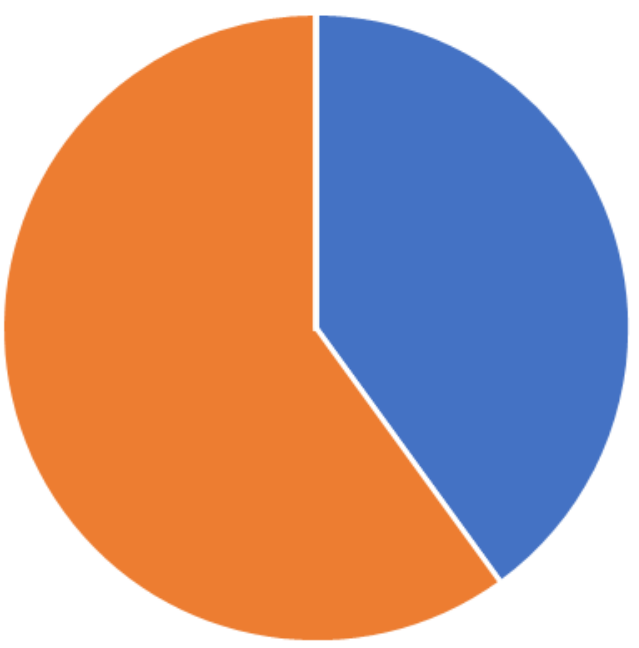

- Very Helpful $\quad$ Somewhat Helpful $\quad$ A Little Helpful $\backsim$ Not Helpful

\section{Figure 4: Ch. 2 Workshop Two Survey Feedback: Same Groups}

Within the same small group, however, there was also recognition that there was not as

much that the group could offer. In example $\mathrm{H}$, the student indicated that the workshop was only "A Little Helpful", that it was "less helpful than last week because this is a piece that is closer to being completed so there are less things to edit." The student did not get as much feedback from their second draft because they felt it was closer to being completed. Whether it was that the paper was near completed, and the student did not have much to change, or that the old set of eyes could not add any new perspective, is hard to say.

For the students in different groups, as seen on Figure 5, they recognized the usefulness of different groups, most students ( 9 out of 10 or $90 \%$ ) reporting the workshops as "Very Helpful/Somewhat Helpful". The student in example I thought that the second workshop was the more useful one. "I was able to get more perspectives on my work and was able to get good advice as to how it could be improved." The recognition of different peer editors emphasizes 
how it is the perspective of other students, not the act of workshopping itself, that is what helps to improve a piece of writing.

\section{Workshop Two Survey Feedback: Different Groups}

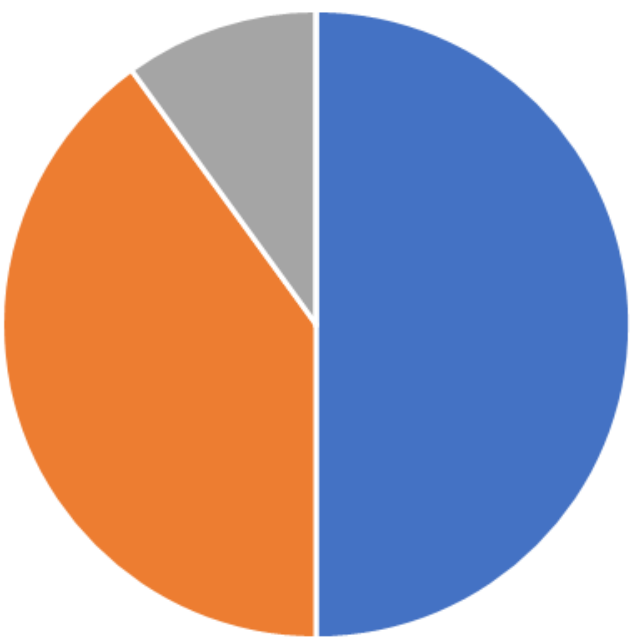

- Very Helpful - Somewhat Helpful = A Little Helpfu $\quad$ Not Helpful

Figure 5: Ch. 2 Workshop Two Survey Feedback: Different Groups

In example J, the student recognized how this workshop was not as helpful as the first,

stating "this is a piece that is closer to being completed so there are less things to edit." This student reported the workshop as "Somewhat Helpful," but did not attribute it to the group, instead focusing their opinion of the progress of the piece. Seeing the work as near finished, there was less to discuss in the workshop.

The student who rated the second workshop as "A Little Helpful" in example K, cited the lack of communication as the issue with the second workshop. "We honestly didn't really critique each other," example K explained. "It's hard to critique without knowing what's most important to focus on while reading each other's work." Much like what Trimbur and Pratt suggest, some workshops do not mesh well. If a small group workshop does not communicate well, it could cause an issue within the workshop, preventing it from being successful. Though 
this was as a result of changing group members for the small group workshops, one could argue that alternating groups could prevent a less than successful workshop repeating. This way, students, even if they did not feel like they had good feedback once, have another chance to get constructive feedback.

\subsection{Case Study Alpha: Results}

The first case study, which I named Alpha, belonged to a student who remained in the same small group workshop for both the first and second drafts. In this narrative, the student describes their relationship with their roommate when an issue of spiders came up, and explores how that changed their perception of the roommate, once considered a friend, now understood to be immature and not a good roommate.

The first draft was a half-completed piece with 392 words (see Appendix Seven). It had a strong hook of "It wasn't until the falling out with a friend that I realized the importance of maturity." A major chunk of the text was written out describing the perception and feelings, stating "This was a unique and frustrating experience" yet avoided too much description of the actual event. The student indicated where they would expand with brackets in the middle and the end, describing the goal, such as "[S]light background on what happened, without going into too much detail]" placed between the first and second paragraph. Another important detail is the student never refers to the roommate by name, opting instead in describing them as "this person" instead.

The second draft expanded to a near completed piece, 821 words long (see Appendix Eight). The first sentence, the hook, became a separate paragraph, which offers a strong statement and a pause. The paragraphs suggested with brackets were filled out with description. The first bracket example earlier became a fully described narrative: "The drama began with a request for extermination. With black widow spiders surrounding our house, my roommates and 
I were justifiably concerned, and I reached out to the landlord in hopes that they would take care of the situation." This information is what was described in the brackets on the previous draft, suggesting the workshop may have influenced them onto how to explain that part of the piece. Another key difference between the first and second draft is the identification of the other roommate as "C," one of the main issues I identified in the first draft.

The third draft ended at 916 words (see Appendix Nine). The additions to this final draft helped to create more details. In the paragraphs stretching between the second and third page, the writer started with "I placed such a larger emphasis on presenting myself as open to compromise" in the second draft, and expanded it to "I placed such a larger emphasis on presenting myself as open to compromise following the event, and I took the perception changes of her and I as a push to become a better version of myself" in the third. The sentence in the third draft expands on the thought, focusing on the issue of perception change, instead of just compromise. Other language tightened up, such as the final paragraph. In the second draft, the paragraph started with "Additionally." In the third draft the writer changed it to "Lastly, and most importantly," helping to sum it up and drive the conclusion.

\subsection{Case Study Beta: Results}

Case Study Beta represents work from a student who switched small groups between workshops one and two. In this example, the student wrote about coming out to their parents. Coming from a religious family, the student explores how their perception of their parents changed along with that of themselves.

The first draft had only two completed paragraphs for 328 words, but the writing in it read like that of a finished piece (see Appendix Ten). It had a strong opening paragraph, with a good flow. The first paragraph explored the perception change in the last sentence stating “Through my personal discovery of who I truly am, many perceptions and views on the world 
changed in my eyes." Then the next paragraph drew you in more with the first sentence.

"Growing up religious, I saw the way my church reacted to the LGBTQ community and it was very negative." The language was straight forward and built off the thoughts of the first paragraph. The student also had notes on the bottom of where to go, with suggestions such as "Perception of myself and mom changed," "Believed in myself" and "The biggest perception that changed was myself.” These showed they knew the path of the essay.

Between drafts one and two, the narrative increased to 524 words, but still did not have a clear, beginning, middle, and end (see Appendix Eleven). The first two paragraphs, aside from fixing the typo of "tendanies" remained verbatim without any edits. The changes came with two additional paragraphs. The first new paragraph was about coming out, but the details were skim, but two the point, stating "Coming out to my parents was the most difficult change I had yet to truly face. I never wanted to come out to them because I felt like I would not be accepted and loved by them." Though telling the moment, it still does not explore the moment. The next paragraph explored the change in perception with "I believed I could not be helped and that I would always be sad. Through many friends and my own self discovery, I grew and bloomed into who I am today." At the end, the same bulleted notes were left as a reminder for the writer on the goals for the final draft.

The third draft lengthened to 729 words, and read like a completed piece, with a clear beginning, middle, and end (see Appendix Twelve). Again, the first two paragraphs remained the same. The third paragraph, the one where the student wrote about coming out, expanded from 61 words to 189 , more than tripling. It expands on how they truly felt in the situation, explaining "My parents are my biggest supporters now because they believe in me and know that I should be able to love whoever I want. During this agonizing process in life, I was set on the concept 
that nothing would ever change and that the relationship I had with my mom would never be positive." This quote shows a distinct change with the first sentence, yet starts to look at how it was before, engaging in the prompt. The third draft then closed with a strong conclusion of "My coming out experience not only strengthened me, but taught me self love, something everyone should learn and possess." It summarizes the main point of the piece and drives it home for the reader.

\subsection{Case Studies Alpha and Beta: Analysis}

These two examples land on opposite sides of the spectrum. Where they are just two of the 18 students and the changes writing cannot be completely attributed to small group workshops, the results seem to suggest that staying in the same groups will help strengthen the flow and language of the work, while changing small groups help to expand ideas.

In Alpha, the student seemed to know where they were going. Between drafts one and two was where the major edits of the piece were done. Between drafts two and three, there were about a hundred words added, but as stated above, the additions became more about strengthening the argument and solidifying the language. This progression mirrors the description Lamott gives about drafts: the first is to get an idea, the second is to make clearer and add information, and the third is to fix up the more superficial mistakes.

In switching groups, Beta made some major additions between each of their drafts. From the notes at the bottom of the page, the student came in with an idea on where the piece should lean toward. That being said, after each small group workshop, the student came back with a more in-depth piece. The additional information added between the second and third drafts about the parents helped to show the perception change, strengthening the piece. This implies that a different group workshop could help create a deeper perspective. 
The results overall show a drastic change between the first drafts and the third drafts. This, of course, was influenced by the design of my first draft, only needing to be a page in length, however both showed growth. Though Alpha showed more details added line-by-line, and Beta expanded by continuing the narrative, they both showed significant growth. 


\section{Chapter 3: Research Paper}

The prompt for my expansion paper, based off my textbook Writing About Writing, goes as follows:

Pick a Chapter topic: Threshold Concepts, Literacies, Individual in Community, Rhetoric, or Processes. Describe what this concept means to you. Use the readings, in-class activities and writing assignments to describe the concept, why it is important, and how you utilize this technique in your own writing.

This will be 1000 to 1500 word Research Paper, using three sources, properly referenced, (one should be from that chapter in "Writing About Writing"). The paper will examine the subject thoroughly, make a case for and against the point you are trying to make.

\subsection{Variables}

Even more than in the personal narrative workshops, these sets of workshops did not go according to plan. The first workshop had 15 students show up, allowing me to break them up into five groups of three. The second workshop only had 12 students show up, and because of a few absent students showing up, more students absent for this workshop, and a few late showups, the plans for the workshops fell apart. Some workshops had completely new participants, where others had two similar ones, with one new voice added late. In the end, the breakdown of the workshops became indiscernible, and I decided to focus on the students' feedback in how helpful each workshop was.

\subsection{Workshop One: Survey Analysis}

Out of the 15 students participating, four (26.67\%) reported the workshop was "Very Helpful", nine (60\%) reported it was "Somewhat Helpful", and two (13.33\%) reported it was "A Little Helpful” (examples in Appendix Five).

Being the third set of workshops, the students showed an understanding of what was expected and how to utilize it best. As shown on Figure 6, the feedback was mostly positive, 
with 13 out of $15(86.67 \%)$ of students reported positive engagement of "Very

Helpful/Somewhat Helpful”. Again, the two students (13.33\%) reporting the workshops as "A Little Helpful" also identified the feedback as useful, despite less than positive reporting.

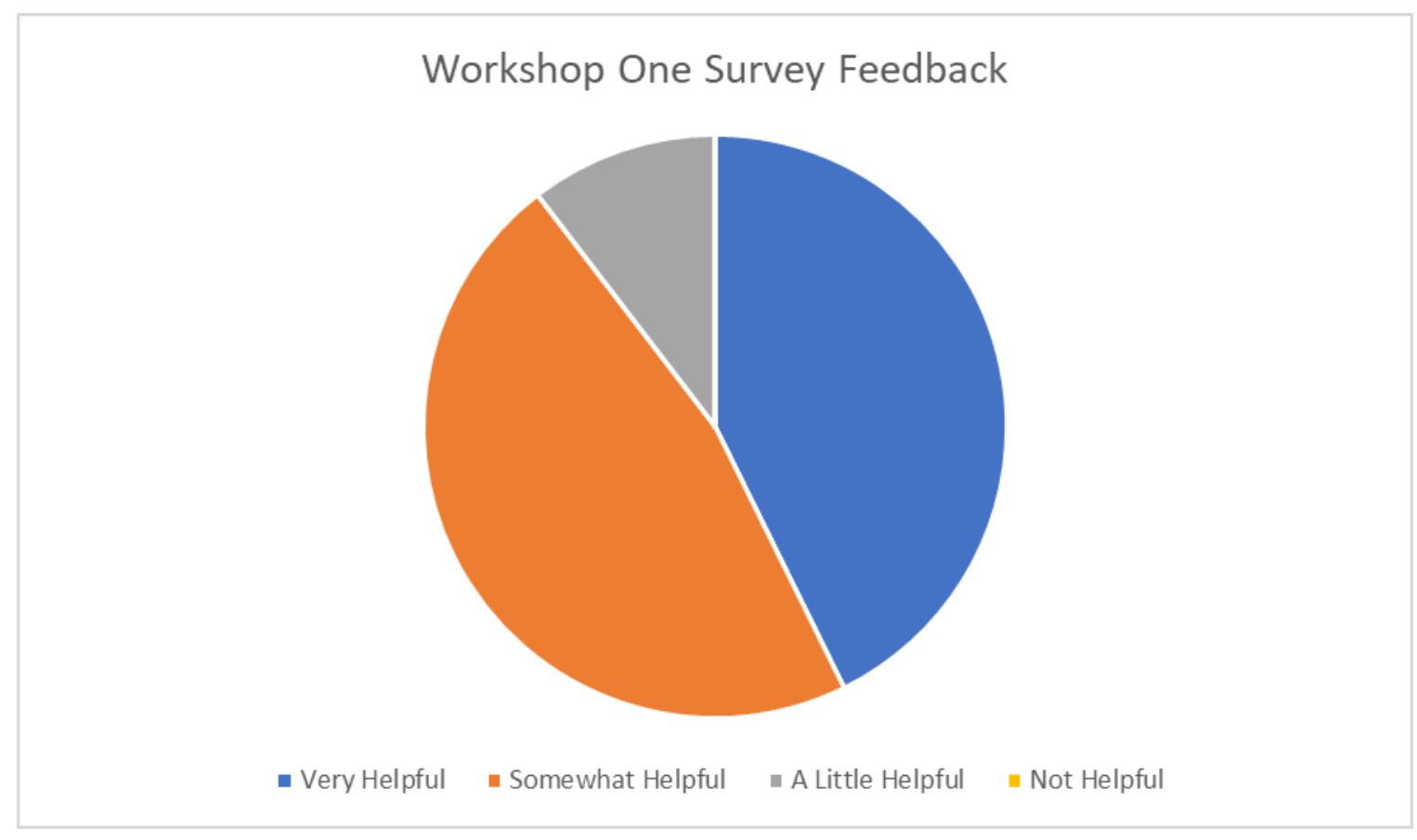

Figure 6: Ch. 3 Workshop One Survey Feedback

Those who reported the workshops as "Very Helpful" took advantage of the loose rules

of the first workshops by using it as a stepping stone to draft two instead of a full, complete draft. From Appendix Five, example L explains "My group helped clarify what my focus should be. They let me know aspects my writing was missing that would help make it more analytical and not just a narrative." In this sense, the student is using this feedback to guide them to how to complete the piece. Likewise, the student in example M stated "[I]t was helpful because I was not very confident about what I have written so far, but after getting the peer review, I feel like I'm on the right track." Here, the first workshop became a confidence booster, urging the writer to continue even if they felt hesitant. 
Likewise, those who reported the workshops to be "Somewhat Helpful" also reported that the first workshop helped with guidance on where to go. In example N, the student states "This workshop was helpful because I got some ideas on where to go with my essay because when I was writing I really did not know what I was supposed to write at all." With peers helping to guide the student forward and taking the next step. The student goes on and states "However, I don't think it was as helpful as other workshops because we all are very confused on this topic so when I was asking my peers questions they didn't know what to say because they are also confused." Where I try to make open-ended essay questions so students could make it their own with their own personal experiences, I recognize that this assignment was not completely clear. This also being my first class I taught I could not use former student's essays as examples. I tried to clarify with explanations in class, but this shows an example of my failures on that front.

Example $\mathrm{O}$ also reflected this thought, explaining "Since this topic is very open-ended and a little intimidating, it was helpful to see how others are approaching the topic. We were able to help each other come up with ideas for how to carry on with the essay when we felt stuck." In this explanation, however, the student pinpoints another goal of workshops: to help clarify the point without the input of the instructor. With Elbow's goal of the teacherless classroom, this allows students to parse through the prompt and come up with solutions.

Even with negative feedback, those who stated the workshops were only "A Little Helpful”, the students still took something out of the experience. In example P, the student recognizes that the first draft was a skeleton of the final piece. "This workshop did give me confidence to continue writing my paper because my group said that everything I wrote so far was clear and makes sense" or, in other words, workshops help to boost confidence, and from that push students to create a better piece. 


\subsection{Workshop Two: Survey Analysis}

Out of the 15 students participating, four (26.67\%) reported the workshop was "Very Helpful", nine (60\%) reported it was "Somewhat Helpful", and two (13.33\%) reported it was "A Little Helpful” (examples in Appendix Six).

Figure 7 shows that this was the first workshop where $100 \%$ of the students, all 12, reported the workshop as being mostly positive, either "Very Helpful" or "Somewhat Helpful." This could be a result of many things, including that students thought that reporting positive feedback was what I wanted.

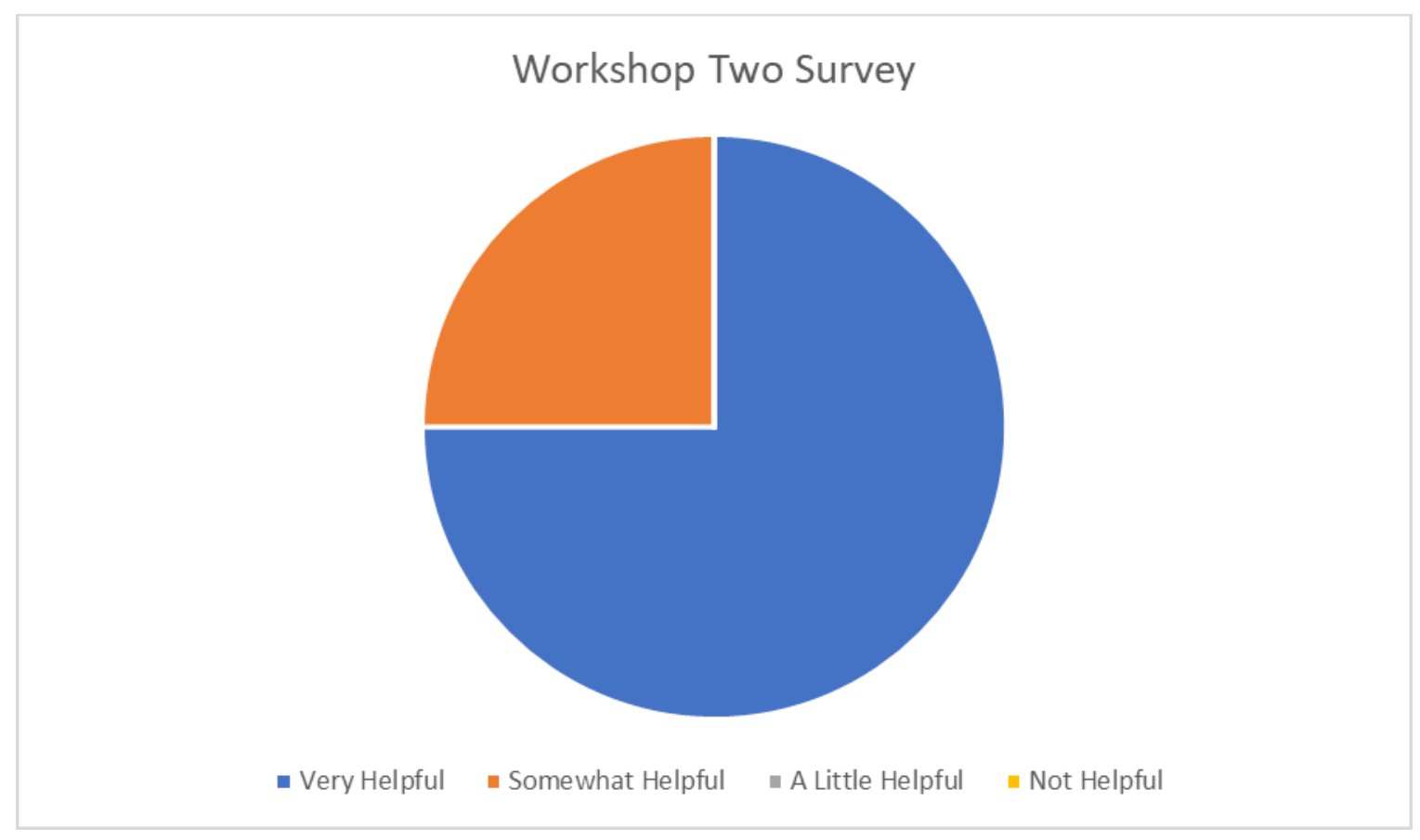

Figure 7: Ch. 3 Workshop Two Survey

In example Q the student, who reported the workshop as "Very Helpful", stated "It was more helpful because I had more writing to edit. I also got some feedback that I was on the right track which was good because I was second guessing myself and almost changed what I was writing about." Focusing on the improvements between drafts, the student views this workshop as a more important one when it comes to solidifying the writing. They also recognize that the 
workshop encouraged them to continue on, again emphasizing the confidence boost of workshops.

In another "Very Helpful" example, R, the students explained that the workshop was "very helpful because I got new perspectives on my work and they helped me come to the conclusion that my paper is ready to be turned in." In one of the small groups that had completely different groups, this student fed back into my original point about new small groups giving new points of view.

Going on to those who reported the workshop to be "Somewhat Helpful", example S had a student explain "[F]irst draft workshops are typically much less helpful than the more finalized drafts being revised. I think this one was helpful because there was more finished ideas to work off of." Recognizing how the first draft was rougher, they put more emphasis on the second draft because it had more for their peers to go over.

Through this mess of a workshop, however, example T gave me one of the more unique perspectives, stating the workshop was " $[\mathrm{H}]$ elpful because I had someone who had been in my group and someone who was not in my group so I got two different perspectives. The person who was in my group last week was able to see how my writing has grown and the person who was not in my group was able to give me a new perspective to see what I could change." Where my main goal was to compare workshops with the same students, and workshops with different students, I never set a goal of combining the two ideas. It feeds off the best of both worlds: getting feedback on how the piece has improved, and a different feedback that could improve the piece further. 


\subsection{Case Study Gamma: Results}

I chose example Gamma because I overheard the student in class discussions explain how they changed their topics between the first and second draft, saying, “After reading other people's papers, I felt the new topic was easier to explain."

The first draft focused on the concept of Process, the fifth chapter in Writing about Writing where we break down the writing process, reaching the 242-word mark (see Appendix Thirteen). The writer engaged personally with the piece, starting with the sentence "[M]y writing process often begins with a lot of thinking about the topic that I am going to discuss.” They then explore what their Process entails, explaining "I write down all thoughts that come to my mind without much rhyme or reason. This helps me get all things relevant to the topic on to the paper so I don't forget anything significant." Though the student explores their own Process well, they also do not engage in any scholarly text.

The second draft changed the topic to Discourse Communities, 644 words, opening with the sentence "While people who write tend to focus on things such as plot structure, rhetoric, and syntax, they often forget to think about discourse communities which is important when thinking about what kind of people will be reading a specific piece of writing." (See Appendix Fourteen). This demonstrates the same connection with the subject as the first. Yet, farther down in the essay, you can see the author being able to connect back to the scholarly text with statements like "The parliamentary debate consisted of a group of students that shared similar values and ethics to work towards a common victory. This discourse community shared a certain set of goals, lexis, and genres in order to collaborate and succeed as a team." This example from the second paragraph clearly uses an example of a Discourse Community, and uses actual scholarly description as reference, referring to goals, lexis, and genres as aspects of a Discourse Community. This was something the student lacked in the first draft. 
The third draft just reached the minimum with 1007 words (see Appendix Fifteen). Similar to Beta, Gamma kept much of what they wrote the same. For example, the first and second paragraphs on the second draft remained verbatim, with not a single spelling or spacing changed. It did, however, fill in some missing pieces. In the third draft, the author adds a paragraph first and second paragraphs of the second draft. This paragraph explains "It is a known argument that using a "discourse community entails assumptions about conformity and convention" meaning that in writing, it brings the audience and readers a sense of security and it hooks them." This quote breaks down the concept of Discourse Communities, adding to the academic portion of the work. One thing missed through the entirely of the drafts, however, was proper citing, proving that there are some things that slip through all the cracks.

\subsection{Case Study Delta: Results}

For example Delta, the student took advantage of the varying requirements of the drafts. This student chose to explore the topic of Process, using the academic texts to analyze what scholars think about Process, while also examining their own.

The first draft was 416 words and made in outline form (see Appendix Sixteen). They had simple tags for the beginning of the essay, with bullets of "Hook/intro" and argument where they have a sub-bullet describing "[E]ach writer creates unique text with crucial skills that include utilizing resources, knowing multiple languages, and having flexible rules." These notes are not detailed, but help to show the writer has a set path. The author also organized two body paragraphs in bullets, where the first examines Stacey Pigg's "Coordinating Constant Invention" and Mike Rose’s “Rigid Rules, Inflexible Plans, and Stifling of Language: A Cognitivist Analysis of Writer's Block." The next two bullets break down their own writing process. They use examples of "In the in-class activity, I started my process by writing full sentences on my paper because I had a limited amount of time." This quote refers back to a timed activity I held in 
class, and helps as a guide to the goal of the paragraph. The outline ends with "Conclusion" noting that they still haven't summed up the piece.

For the second draft, the writer turned in a well-designed, completed piece of 1306 words (see Appendix Seventeen). Where the author in the first draft left places for the introduction and conclusion, the second draft starts out with "[W]hen an individual hears of the word "process", he or she thinks of a set of directions or steps on how to complete a task." This strong introduction reflects the "hook" they noted in the first draft. The paragraphs followed the outline, starting with the analysis of text in the second paragraph, starting with "To begin with, all writers create good text by using resources. In "Coordinating Constant Invention" by Stacey Pigg, she discusses how technology facilitates a person's writing process (Pigg, 713)." This text looks similar to the outline, but is more drawn out, detailed, to help drive the thesis. Interweaving the personal with the research, the student adds a strong conclusion, explaining "Ultimately, Writing About Writing has helped me realize my own writing process. Although I used to be self conscious about my writing, taking pride in my process and in my work has helped me gain confidence. By utilizing resources, being okay with errors, and having flexible rules, I am able to write to my best ability." Here, it shows both reflection on their own Process, as well as the concept of Process as a whole.

The second draft presented as a finished piece, so much so that the only difference between the second and third draft was a hyphen between "first-year" once and "self-conscious" twice, lowering the whole word count by three (see Appendix Eighteen). Still, all the surveys were rated as "Somewhat Helpful" or "Very Helpful" reflecting that though the student did not change anything, they stated that they something out of the workshop. 


\subsection{Case Studies Gamma and Delta: Analysis}

These two examples bring up some interesting points when it comes to workshopping: that students get different things out of workshops in different situations. For example, example Gamma came in with a topic that, at that point, did not resonate both personally and academically. Once finished with the first set of workshops, the student went home and decided to take a completely different turn with the essay. Verbally confirming that their fellow students helped influence them, example Gamma was able to connect with this second topic better and create a finished piece.

After a semester in my class, example Delta took advantage of my lax first draft rules and came in with an outline. This outline, however, was clearly detailed and not bare bones. This approach allowed the student to formulate their argument, get support and confirmation from their fellow workshoppers, and continue forward. The second workshop did not seem as helpful, only three small, grammatical errors, adding three hyphens to shorten the word length by three. One possible conclusion could be that the positive feedback that was received by the student helped create a successful workshop, whether or not they changed much.

Neither of these examples reflect some of these major points in the surveys after the workshops. Nothing in any of the anonymous surveys explained how example Gamma was able to change topics to one they connected with more. This could be a result of the survey being given right after the workshops, and that the student did not decide to change their mind until going home and sitting down to write the second draft. If that's the case, then it shows that the act of workshopping extends beyond just sitting in the classroom.

As for example Delta, what is perplexing is that there was little to no growth between drafts two and three (the final), yet still the student filled out the survey, meaning that they either reported the workshop "Somewhat" or "Very Helpful". How was that workshop helpful in a 
positive way if almost nothing changed? As argued by Elbow and Holaday, the positive feedback could come from a workshop at that point is reaffirmation that the paper is completed and ready to turn in. If that were true, then the benefits of workshopping go beyond the page, and reinforces confidence in writers. 


\section{Chapter 4: Conclusion}

After looking at the feedback in the surveys, and examining the differences in drafts, I can see how encouraging students to engage with their work early and often helps to strengthen their writing. As Anne Lamott explains, “Almost all good writing begins with terrible first efforts. You need to start somewhere. Start by getting something - anything - down on paper" (855). In my students' first drafts, many came in with works-in-progress. The biggest changes in each student's writing came between the first and second draft.

For the first set of workshops, the second small group workshop caught my interest. The results of the second draft lean toward the conclusion that switching peer workshops is a helpful practice for the students. Though this is a small pool of results to draw from, both the survey responses and the case studies helped to support this suggestion. The survey feedback was overwhelmingly positive, yet those who switched small groups had higher marks of approval (even though the only negative-leaning comment was in this group). Their comments suggested that they thought that different sets of eyes reading their piece helped them to get a clearer picture on their work. Different perspectives and different approaches don't necessarily force the writer to alter their work to appease the readers, but they do help to show what a reader sees, giving the writer a fuller picture of how their work comes across.

The negative feedback in the first set of surveys may have argued against the changing of small groups, but the actual feedback helps strengthen the argument. The student cited bad group dynamics as the reason or the workshop not begin completely effective. Yet, if this student had this experience in the first draft workshop and remained in the same group, the same disfunction 
would follow in draft two. In this sense, changing peer workshops creates a variable, but allows for the ability to amend problematic situations.

The case studies solidified this argument. Again, these are only two examples from a small testing pool, but example Alpha, who remained in the same group, showed very little change when it came to content and more of a change when it came to line-by-line edits, while example Beta in a different group showed more change in content while the line-by-line writing remained closer to the same.

The haphazard way the second workshops fell together added a different wrinkle in my analysis. The added layer of workshops having both new and previous workshoppers in the second workshop showed me there was no one answer to this "workshop process" issue. The positive reinforcement from peers is the main takeaway from workshops and where switching up groups could prevent stagnancy and bad blood, the workshop is about the encouraging environment, not the people per say.

Looking at Case Studies Gamma and Delta, it is clear that students will find their own successes in workshops. The writer of example Gamma changed their mind on a topic, and because of it was able to write a more cohesive piece in the second and later third draft. Example Delta, on the other hand, brought their own outline as a first draft, built a completed essay for the second draft and, though barely edited it for the third, gained enough confidence in the second workshop to consider it successful.

So where does that leave this study? In many ways, it becomes more complicated, not giving a concise answer to what workshop method is better. In the end, this study has suggested to me not only the efficacy of workshops, but the need for variety within the classroom. In focusing on what I foresaw as a minor change in my pedagogical approach, I realized the vast 
difference a simple change of small groups could create. As my original approach was to focus on one specific way of workshopping, I see now that need to explore different types of workshops for my students. Each student has a different approach to writing, and allowing students to explore different techniques of workshopping can help them not only be better readers, but create better works of writing. 


\section{Works Cited}

Barnard, Ian. "Whole-Class Workshops: The Transformation of Students Into Writers" Issues in Writing, vol. 12, issue 2, Spring/Summer 2002, pp. 124-143,University of WisconsinStevens Point.

Bedore, Pamela; and Brian O’Sullivan. “Addressing Instructor Ambivalence about Peer Review and Self-Assessment" WPA: Writing Program Administration, vol. 34, no. 2, Spring 2011, pp. 11-36. http://www.wpacouncil.org/archives/34n2/34n2bedore-osullivan.pdf.

Bellas, Ralph A. "Workshop Sessions in English Composition." College Composition and Communication, vol. 21, no. 3, 1970, pp. 271-273. JSTOR, www.jstor.org/stable/357332.

Brammer, Charlotte; and Mary Rees. "Peer Review from the Students' Perspective: Invaluable or Invalid?" Composition Studies, vol. 35, no. 2, 2007, pp. 71-85. JSTOR, www.jstor.org/stable/43501704.

Brooke, Robert; Ruth Mirtz; Rick Evans. Small groups in writing workshops: Invitations to a writer's life. National Council of Teachers of English, 1994 [ERIC Document Reproduction Service, ED 372 389].

Bruffee, Kenneth A. "The Art of Collaborative Learning: Making the Most of Knowledgeable Peers.” Change, vol. 26, no. 3, 1994, pp. 39-44. JSTOR, www.jstor.org/stable/40165217.

Downs, Doug and Elizabeth Wardle. Writing About Writing: A College Reader. Bedford/St. Martins, Third Edition, 2017.

Ede, Lisa, and Andrea A. Lunsford. "Collaboration and Concepts of Authorship." PMLA, vol. 116, no. 2, 2001, pp. 354-369. JSTOR, www.jstor.org/stable/463522.

Elbow, Peter. Writing Without Teachers. Oxford University Press, 1998.

Graner, Michael H. "Revision Workshops: An Alternative to Peer Editing Groups." The English Journal, vol. 76, no. 3, 1987, pp. 40-45. JSTOR, www.jstor.org/stable/818540.

Harris, Muriel. "Collaboration is Not Collaboration Is Not Collaboration: Writing Center Tutorials vs. Peer-Response Groups." College Composition and Communication. Vol. 43, No. 3 (Oct. 1992): 369-383.

Holaday, Lynn. "Writing Students Need Coaches, Not Judges." Alternatives to Grading Student Writing. Ed. Stephen Tchudi. Urbana, IL: NCTE, 1997. 35-46.

Lamott, Anne "Shitty First Drafts." Writing About Writing: A College Reader, edited by Elizabeth Wardle and Doug Downs, Third Edition, 2017, pp. 852-857, Bedford/St. Martins. 
Pratt, Mary Louise. “Arts of the Contact Zone." Profession, 1991, pp. 33-40. JSTOR, www.jstor.org/stable/25595469.

Trimbur, John. "Consensus and Difference in Collaborative Learning." College English, Vol. 51, No. 6, Oct. 1989, pp. 602-616. 


\section{Appendices}

\section{Appendix 1: Workshop One Survey}

1. How helpful was the workshop (highlight one)

Not Helpful A Little Helpful Somewhat Helpful

Very Helpful

In what way was it helpful or not helpful: 


\section{Appendix Two: Workshop Two Survey}

1. Were you in the same workshop as last week (highlight one)?

Yes

No

2. How helpful was the workshop (highlight one)?

Not Helpful A Little Helpful

Somewhat Helpful

Very Helpful

3. How helpful was this workshop? Was it more or less helpful than last week? Why or why not? 


\section{Appendix Three: Personal Narrative Workshop One Survey Examples}

Out of the 16 students, seven (43.75\%) reported the workshop was "Very Helpful", seven (43.75\%) reported it was "Somewhat Helpful”, and two (12.5\%) reported it was "A Little Helpful".

A - Very Helpful "It was helpful to hear about what I was doing right. I was unsure if I followed the prompt correctly but everyone agree that I was. It was also helpful to have feedback about what I could add on or what I may have missed out."

B - Very Helpful "I find it very helpful because there is more than one perspective on my work. Everyone has a different approach to their writing therefore getting multiple perspectives is essential to making your work better. I think the time works well and in ten minutes we can see what it is we are doing well and what it is we should improve. I enjoy the workshops because you get to learn about someone while still being academic and getting feedback."

C - Somewhat Helpful "I think that this was helpful because I got to hear other people's perspective on my writing piece. When other people read my piece, they give me opinions that I didn't think about prior to hearing it from them which is useful. It wasn't extremely helpful because I felt that my paper wasn't a rough draft, rather it's very close to being complete so they did not have many suggestions for me about how to edit it, but the suggestions they did give me were helpful and I used it in my paper. If I have an extremely rough draft then it would be beneficial to me because they would help me form the piece and help give me ideas on how to structure my piece." 
D - Somewhat Helpful "I think today's workshop was somewhat helpful because our narratives are still so short and incomplete, it was hard to really work on them and make suggestions. The next workshop however I feel will be much more helpful since we will have our completed pieces and able to focus on ensuring that the change in perspective is made clear and that the other aspects of the narrative are present as well."

E - A Little Helpful "This workshop was helpful because I was able to bounce ideas off of my group members about where I was going with this piece, and have them provide feedback about the overall organization of my work. However, it was difficult for all of us to use the full 10 minutes to workshop, due to the length of the draft. Because there were many ideas and explanations missing from our first drafts, it was difficult to critique the incomplete work." 


\section{Appendix Four: Personal Narrative Workshop Two Survey Examples}

The survey feedback for the second set of workshops was similarly successful with positive feedback. Out of the 17 students overall, nine (52.9\%) reported the workshop was "Very Helpful", seven (41.18\%) reported it was "Somewhat Helpful", and one (5.88\%) reported it was “A Little Helpful”.

For the two students absent during the first workshop, both of them (100\%) reported the workshops were "Very Helpful". Here is a section of the feedback from one of the surveys:

F - "This workshop was very helpful because it gave me the opportunity to get feedback from my peers on what I need to improve on in regards to my personal narrative... I have had experiences with writing workshops in the past and they have always proven to be a big help because you are able to learn from your peers and get advice on what should be changed and what should remain the way it is. I was not at the workshop last week...My peers gave me some good advice on what I should do for my third draft, I am feeling confident that my third draft will be great."

Out of the five students in the same small groups for both workshops, two (40\%) reported the workshop as "Very Helpful" while three (60\%) reported the workshop was "Somewhat Helpful". This was the only set of responses where the majority did not choose "Very Helpful".

Here is a selection of the feedback from the students in the same groups:

G - Very Helpful "It was more helpful than last weeks because now that I am close to my final draft I was able to get much more complete feedback. I saw what I was still missing and got 
advice on how to incorporate it into my narrative since my partners were able to get a sense of the whole story. It will help me polish it up and answer the question as best I can.”

H - Somewhat Helpful "This workshop was a lot more helpful than last weeks due to the completion level of our work. With a more complete version of the personal narrative, my group members and I were able to provide more solid feedback. Additionally, it helped having the same group members as the first workshop, because they were able to see exactly how my work had changed since the first draft, and vice versa."

When it came to the 10 students in different small group workshops, five (50\%) reported the workshop was "Very Helpful", four (40\%) reported it was somewhat helpful, while only one (10\%) student stated the workshop was "A Little Helpful".

Here are some explanations about how the new small groups helped the students: I - Very Helpful "The workshop was more helpful from last week. I was able to get more perspectives on my work and was able to get good advice as to how it could be improved. I enjoy the workshops because they help get different views on a work as everyone has a different writing style."

J - Somewhat Helpful "This workshop was less helpful than last week because this is a piece that is closer to being completed so there are less things to edit. I feel that the rough drafts are way easier to edit and are easier to use during workshops because there are a lot of mistakes in the piece rather than when the assignment is near completed. With a final draft, you already have 
your main ideas written and expanded on so you no longer question what you should write about which results in needing less help from peers.”

K - A Little Helpful "We honestly didn't really critique each other. It's hard to critique without knowing what's most important to focus on while reading each other's work." explanations missing from our first drafts, it was difficult to critique the incomplete work." 


\section{Appendix Five: Expansion Essay Workshop One Survey Examples}

Out of the 15 students participating, four (26.67\%) reported the workshop was "Very Helpful", nine $(60 \%)$ reported it was "Somewhat Helpful", and two (13.33\%) reported it was "A Little Helpful”.

Here are another key set of examples of students describing why they responded the way they did:

L - Very Helpful "My group helped clarify what my focus should be. They let me know aspects my writing was missing that would help make it more analytical and not just a narrative. I think their feedback will help me be able to write out the full essay so that I can have more targeted critique during our second workshop."

M - Very Helpful "It was helpful because I was not very confident about what I have written so far, but after getting the peer review, I feel like I'm on the right track. I just need to clean up a few things and finish it."

$\mathrm{N}$ - Somewhat Helpful "This workshop was helpful because I got some ideas on where to go with my essay because when I was writing I really did not know what I was supposed to write at all. I felt that talking to my peers and reading their papers helped me get more ideas and I feel that I am able to go home and write some more. However, I don't think it was as helpful as other workshops because we all are very confused on this topic so when I was asking my peers questions they didn't know what to say because they are also confused." $\mathrm{O}$ - Somewhat Helpful "Since this topic is very open-ended and a little intimidating, it was helpful to see how others are approaching the topic. We were able to help each other come up with ideas for how to carry on with the essay when we felt stuck. It's always helpful to get an outside perspective and new ideas when we feel stuck in our own writing." 
P - A Little Helpful 'Since it was my first draft, I already knew it wasn't perfect. Before the workshop, I already knew what I had to improve on, so the comments weren't too surprising to me. I am missing a lot of content in my paper, but that is because I only wrote 300 out of 1500 words so far. This workshop did give me confidence to continue writing my paper because my group said that everything I wrote so far was clear and makes sense.” 


\section{Appendix Six: Expansion Essay Workshop Two Survey Examples}

Out of the 12 students workshopping, nine (75\%) reported it was "Very Helpful" and three (25\%) reported it was "Somewhat Helpful."

Here are some key examples of feedback:

Q - Very Helpful "It was more helpful because I had more writing to edit. I also got some

feedback that I was on the right track which was good because I was second guessing myself and almost changed what I was writing about. I also liked seeing that other people were incorporating personal experiences into their writing like I am because that helps me feel like I'm doing something right."

R - Very Helpful "It was very helpful because I got new perspectives on my work and they helped me come to the conclusion that my paper is ready to be turned in. I enjoyed switching groups because of the new perspectives. I think it was more helpful than last week because I had more content to review and give my peers."

S - Somewhat Helpful "First draft workshops are typically much less helpful than the more finalized drafts being revised. I think this one was helpful because there was more finished ideas to work off of."

T - Somewhat Helpful "Helpful because I had someone who had been in my group and someone who was not in my group so I got two different perspectives. The person who was in my group last week was able to see how my writing has grown and the person who was not in my group was able to give me a new perspective to see what I could change.” 


\section{Appendix Seven: Case Study Alpha Draft One}

It wasn't until the falling out with a friend that I realized the importance of maturity. Maturity is something I believe we all subconsciously seek out as we form our interpersonal relationships. As we form friends, we seek out whether they are too immature at inopportune times, or exhaustingly mature when it's time to let loose. It's the people that closely match our own concepts and levels of maturity- and immaturity- that stick around for the long haul. This is something that often takes time to gauge, and personally, it has never been at the forefront of my mind as I get to know people. It wasn't until I lived with a friend that handled an unfortunate situation like a pre teen at 22 years old that I fully understood what I find important in the people I surround myself with.

[Slight background on what happened, without going into too much detail]

Following the experience were various conversations among the roommates, venting our feelings, and trying to figure out the best way to handle the situation that had gotten away from us. Somehow, we had done everything we could in handling it maturely, but the responsibility of repairing the damage to the relationships- that our other roommate had caused- fell onto our shoulders. This was a unique and frustrating experience.

It was in the midst of this that my perception of this person completely changed. It's easy to overlook wrongdoings of a person overtime when they're subtle, and feel silly to address. However, when reflecting with hindsight, I, along with my other roommates, saw the underlying issues we had been putting up with for so long. We saw not only the manipulation leading us to always do things her way, but we also saw the absolute lack of 
maturity exhibited on her end throughout the time we had known her. My perception shifted from seeing this person as a silly, slightly oblivious girl, to someone that was content with never having to make sacrifices for those around her, or put in the effort needed to maintain a healthy relationship. Because I take pride in my ability to generally see people for who they really are, this realization really impacted me.

[Perception shift on all interpersonal relationships, and how I subsequently want to present myself as a friend, girlfriend, daughter, etc.] 


\section{Appendix Eight: Case Study Alpha Draft Two}

It wasn't until the falling out with a friend that I realized the importance of maturity.

Maturity is something I believe we all subconsciously seek out as we form our interpersonal relationships. As we form friends, we seek out whether they are too immature at inopportune times, or exhaustingly mature when it's time to let loose. It's the people that closely match our own concepts and levels of maturity- and immaturity- that stick around for the long haul. This is something that often takes time to gauge, and personally, it has never been at the forefront of my mind as I get to know people. It wasn't until I lived with a 22 year old friend that handled an unfortunate situation like a pre teen that I fully understood what I find important in the people I surround myself with.

The drama began with a request for extermination. With black widow spiders surrounding our house, my roommates and I were justifiably concerned, and I reached out to the landlord in hopes that they would take care of the situation. Our landlords are the parents of one of our roommates- I'll refer to her as C- and it turned out that the whole family doesn't believe in extermination. C stood by her parents, and acted as if she were our landlord living in her house. To summarize, we faced with a six week long battle in attempts to rid of the poisonous spiders. During these six weeks, $\mathrm{C}$ avoided us completely and our friendships with her were essentially put on hold. The situation was unfortunate, and the handling of it disappointing, but at the end of it all, it became about much more than the spiders. We were faced with an unfavorable truth about C's personality.

Following the experience were various conversations among the roommates, venting our feelings, and trying to figure out the best way to handle the situation that had gotten away from 
us. C had not talked to us for two weeks, and we didn't know how to go about repairing the relationship. Somehow, we had done everything we could in handling it maturely, but the responsibility of repairing the damage to the relationships- that $\mathrm{C}$ had caused- fell onto our shoulders. This was a unique and frustrating experience.

As the saying goes, hindsight is $20 / 20$, and having this experience left us questioning the things that $\mathrm{C}$ had been doing throughout our friendships with her. Our mindsets were slowly shifting from, "What can we do to fix this mess?" to "Why do we feel the need to fix the mess that she created?" It became clear to us that C had almost never taken responsibility for her actions. We were always left doing things for her, fixing her problems, and receiving nothing in return. During these conversations and realizations, my perception of friendships and who I want surrounding me did a complete 180.

My perception of C completely changed, as well. It's easy to overlook wrongdoings of a person overtime when they're subtle, and feel silly to address. However, during our reflection, the underlying issues we had been putting up with for so long became apparent. We saw not only the manipulation leading us to always do things her way, but we also saw the absolute lack of maturity exhibited on her end throughout the time we had known her. My perception shifted from seeing $\mathrm{C}$ as a silly, slightly oblivious girl, to someone that was content with never having to make sacrifices, or put in effort for the people around her. Because I take pride in my ability to generally see people for who they really are, this realization really impacted me.

The entire experience caused me to analyze not only the actions of the people around me, but also my own actions towards others. Knowing the amount of stress the situation put on me caused me to be fully aware of the way I presented myself to the people I care about. I've always considered myself an approachable person, but following this experience, I placed such 
a larger emphasis on presenting myself as open to compromise. I never wanted anybody to struggle with me how we all did with her.

Additionally, my perception of maturity completely shifted. The maturity levels of the people around me tended to fall into the back of my mind as I let myself develop friendships, whereas now, it is one of the very first things I look for. All in all, I understand and accept that there will be conflicts throughout my life, regardless of who I surround myself with. However, after this experience, I place such a high emphasis on handling those conflicts with maturity, and surrounding myself with individuals who will try their best to do the same. For me, it's not about the conflicts that will inevitably be had, it's about how those conflicts will be handled. 


\section{Appendix Nine: Case Study Alpha Draft Three}

It wasn't until the falling out with a friend that I realized the importance of maturity.

Maturity is something I believe we all subconsciously seek out as we form our interpersonal relationships. As we form friends, we seek out whether they are too immature at inopportune times, or exhaustingly mature when it's time to let loose. It's the people that closely match our own concepts and levels of maturity- and immaturity- that stick around for the long haul. This is something that often takes time to gauge, and personally, it has never been at the forefront of my mind as I get to know people. It wasn't until I lived with a 22 year old friend that handled an unfortunate situation like a pre teen that I fully understood what I find important in the people I surround myself with.

The drama began with a request for extermination. With black widow spiders surrounding our house, my roommates and I were justifiably concerned, and I reached out to the landlord in hopes that they would take care of the situation. Our landlords are the parents of one of our roommates- I'll refer to her as C- and it turned out that the whole family doesn't believe in extermination. $\mathrm{C}$ stood by her parents, and acted as if she were our landlord living in her house. To summarize, we faced with a six week long battle in attempts to rid of the poisonous spiders. During these six weeks, C avoided us completely and our friendships with her were essentially put on hold. The situation was unfortunate, and the handling of it disappointing, but at the end of it all, it became about much more than the spiders. We were faced with an unfavorable truth about C's personality.

Following the experience were various conversations among the roommates, venting our feelings, and trying to figure out the best way to handle the situation that had gotten away from 
us. C had not talked to us for two weeks, and we didn't know how to go about repairing the relationship. Somehow, we had done everything we could in handling it maturely, but the responsibility of repairing the damage to the relationships- that $\mathrm{C}$ had caused- fell onto our shoulders. This was a unique and frustrating experience.

As the saying goes, hindsight is $20 / 20$, and having this experience left us questioning the things that $\mathrm{C}$ had been doing throughout our friendships with her. Our mindsets were slowly shifting from, "What can we do to fix this mess?" to "Why do we feel the need to fix the mess that she created?" It became clear to us that C had almost never taken responsibility for her actions. We were always left doing things for her, fixing her problems, and receiving nothing in return. During these conversations and realizations, my perception of friendships and who I want surrounding me did a complete 180.

My perception of C completely changed, as well. It's easy to overlook wrongdoings of a person overtime when they're subtle, and feel silly to address. However, during our reflection, the underlying issues we had been putting up with for so long became apparent. We saw not only the manipulation leading us to always do things her way, but we also saw the absolute lack of maturity exhibited on her end throughout the time we had known her. My perception shifted from seeing $\mathrm{C}$ as a silly, slightly oblivious girl, to someone that was content with never having to make sacrifices, or put in effort for the people around her. Because I take pride in my ability to generally see people for who they really are, this realization really impacted me.

The entire experience caused me to analyze not only the actions of the people around me, but also my own actions towards others. The perception I held of C clearly changed, but alongside that, my perception of the way I treated friendships changed as well. Aware of the stress provoked by the situation, I strived to ensure I never presented myself in the way that she 
did to the people I care about. I've always perceived myself to be an approachable person, but following this experience, I questioned the validity of that belief. The perception I held of myself changed, as I realized the changes I could make to my own communication skills, and approachability. I placed such a larger emphasis on presenting myself as open to compromise following the event, and I took the perception changes of her and I as a push to become a better version of myself. I never wanted anybody to struggle with me how we all did with her.

Lastly, and most importantly, my perception of maturity completely shifted. The maturity levels of the people around me tended to fall into the back of my mind as I let myself develop friendships, whereas now, it is one of the very first things I look for. All in all, I understand and accept that there will be conflicts throughout my life, regardless of who I surround myself with. However, after this experience, I place such a high emphasis on handling those conflicts with maturity, and surrounding myself with individuals who will try their best to do the same. I used to perceive conflicts in interpersonal relationships as bad, and something to be avoided. Succeeding this experience, I now perceive conflict as something to accept, and to learn from, as they will inevitably be had. 


\section{Appendix Ten: Case Study Beta Draft One}

\section{Personal Narrative}

In light of National Coming Out Day on October 11th, I feel compelled to share my story of coming out and how that changed my perception on many different factors of my life. I grew up in a very religious household where the idea of being gay was never discussed. My mom said that my brother and I would grow up, have a wife and children, and that is what a normal life looked like. There was always a part of me that felt 'different' but because of the way society states what 'normal' is, I just pushed that part of myself away and attempted to grow up as a 'normal' kid. My perception of the world was always, "this is how people believe I should behave so this is how I should act." Through my personal discovery of who I truly am, many perceptions and views on the world changed in my eyes.

Growing up religious, I saw the way my church reacted to the LGBTQ community and it was very negative. I began to believe that the tendanies I possessed were a mistake. I felt like God didn't love me and that I felt this way because I wasn't meant to be there. Through all of this anger and sadness came a bounty of bitterness towards the world. In my eyes, I believed I didn't owe the world anything because I felt so empty and broken. Throughout my youth, my perception of myself what that I was not like other kids and that I should try everything to become normal and fit in with what society believes to be correct. Not only was my perception of myself in poor taste, my perception of everyone around me was negative. I believed no one would accept me for who I am and who I am meant to be. 
Perception of myself and mom changed

Believed in myself

The biggest perception that changed was myself. 


\section{Appendix Eleven: Case Study Beta Draft Two}

\section{Personal Narrative}

In light of National Coming Out Day on October 11th, I feel compelled to share my story of coming out and how that changed my perception on many different factors of my life. I grew up in a very religious household where the idea of being gay was never discussed. My mom said that my brother and I would grow up, have a wife and children, and that is what a normal life looked like. There was always a part of me that felt 'different' but because of the way society states what 'normal' is, I just pushed that part of myself away and attempted to grow up as a 'normal' kid. My perception of the world was always, "this is how people believe I should behave so this is how I should act." Through my personal discovery of who I truly am, many perceptions and views on the world changed in my eyes.

Growing up religious, I saw the way my church reacted to the LGBTQ community and it was very negative. I began to believe that the tendencies I possessed were a mistake. I felt like God didn't love me and that I felt this way because I wasn't meant to be there. Through all of this anger and sadness came a bounty of bitterness towards the world. In my eyes, I believed I didn't owe the world anything because I felt so empty and broken. Throughout my youth, my perception of myself was that I was not like other kids and that I should try everything to become normal and fit in with what society believes to be correct. Not only was my perception of myself in poor taste, my perception of everyone around me was negative. I believed no one would accept me for who I am and who I am meant to be.

Coming out to my parents was the most difficult change I had yet to truly face. I never wanted to come out to them because I felt like I would not be accepted and loved by them. I a 
sense that was partly true. For awhile, it was difficult for my parents to understand and be open to my life decisions.

My perception soon began to change as I discovered more of myself and realized I had to put myself first. I needed to accept who I was before anyone could accept me. During this somber period, I believed I could not be helped and that I would always be sad. Through many friends and my own self discovery, I grew and bloomed into who I am today. In this self reflection, I notice that the largest perception that changed in my life was that of myself. Through the hurt I experienced from my parents and other figures around me, I learned that the only opinion of me that matters is the one I have of myself. I had to learn to believe in myself and know that I am able to love whoever I want.

Perception of myself and mom changed

Believed in myself

The biggest perception that changed was myself. 


\section{Appendix Twelve: Case Study Beta Draft Three}

\section{Personal Narrative: Coming Out}

In light of National Coming Out Day on October 11th, I feel compelled to share my story of coming out and how that changed my perception on many different factors of my life. I grew up in a very religious household where the idea of being gay was never discussed. My mom said that my brother and I would grow up, have a wife and children, and that is what a normal life looked like. There was always a part of me that felt 'different' but because of the way society states what 'normal' is, I just pushed that part of myself away and attempted to grow up as a 'normal' kid. My perception of the world was always, "this is how people believe I should behave so this is how I should act." Through my personal discovery of who I truly am, many perceptions and views on the world changed in my eyes.

Growing up religious, I saw the way my church reacted to the LGBTQ community and it was very negative. I began to believe that the tendencies I possessed were a mistake. I felt like God didn't love me and that I felt this way because I wasn't meant to be there. Through all of this anger and sadness came a bounty of bitterness towards the world. In my eyes, I believed I didn't owe the world anything because I felt so empty and broken. Throughout my youth, my perception of myself was that I was not like other kids and that I should try everything to become normal and fit in with what society believes to be correct. Not only was my perception of myself in poor taste, my perception of everyone around me was negative. I believed no one would accept me for who I am and who I am meant to be.

Coming out to my parents was the most difficult change I had yet to truly face. I never wanted to come out to them because I felt like I would not be accepted and loved by them. For 
awhile, it was difficult for my parents to understand and be open to my life decisions. Through time and healing, their perception of me changed and my perception of myself only became stronger. My parents are my biggest supporters now because they believe in me and know that I should be able to love whoever I want. During this agonizing process in life, I was set on the concept that nothing would ever change and that the relationship I had with my mom would never be positive. As humans, we never truly know how someone will react to us and our choices. Once my relationship with my mom grew stronger, I came to the conclusion that our first perception of a situation is not the one that has to be set in stone. Although my perception of others positively flourished, my perception of myself was the hardest to understand and change.

My perception of myself soon began to change once I discovered who I am at my core. I needed to accept who I was before anyone could accept me. I had to understand that I needed to put myself first and love myself before I could love anybody else. During this transitional period, I believed I could not be helped and that I would always have my own internal battles. Through many friends and my own self discovery, I grew and bloomed into who I am today. In this self reflection, I notice that the largest perception that changed in my life was that of myself. Through the hurt I experienced from my parents and other figures around me, I learned that the only opinion of me that matters is the one I have of myself.

The perceptions we have of ourselves is most important because how we see ourselves is how we perceive ourselves to others around us. No one will ever be able to truly love anyone else unless they love who they are first. Acceptance is key because there might be factors about ourselves we are not happy with, but once one learns to love their flaws, they can learn to love everyone else's. My coming out experience not only strengthened me, but taught me self love, 
something everyone should learn and possess. 


\section{Appendix Thirteen: Case Study Gamma Draft One}

My writing process often begins with a lot of thinking about the topic that I am going to discuss. I tend to go back and forth between what I want to write about. I either have a lot of ideas or none so that poses a challenge about how to begin. For my open letter, I initially thought I would be writing about a political topic that I was passionate about, but after thinking about it, I ended up writing it about mental illness because I thought it better pertained to the prompt.

Once I have a topic that fits the prompt well, I tend to free write to get all of my ideas out, like what I am doing right now. I write down all thoughts that come to my mind without much rhyme or reason. This helps me get all things relevant to the topic on to the paper so I don't forget anything significant. This also occurred during my open letter about mental illness because I began to go on rants and tangents about the issues I experienced.

After all my thoughts are on paper, I organize them into the way that makes the most sense chronologically to get the storyline across. I take all the tangents and group them together in order to get it all to flow nicely. I also group sentences together in order to improve the overall syntax of the essay. 


\section{Appendix Fourteen: Case Study Gamma Draft Two}

While people who write tend to focus on things such as plot structure, rhetoric, and syntax, they often forget to think about discourse communities which is important when thinking about what kind of people will be reading a specific piece of writing. Discourse communities are groups of people that share a common interest, topics, or specific knowledge. This often connects them through similar vocabulary, linguistics, and jargon that is only understood by them. Discourse communities often have a common set of goals that members aim for in order to advance. This goal is helped to develop through lexis to contribute to intercommunication through their unique jargon and genres to articulate how the discourse community gets things done and operates through the linguistics.

An example of a discourse community that I have been a part of is my high school's parliamentary debate team.The parliamentary debate consisted of a group of students that shared similar values and ethics to work towards a common victory. This discourse community shared a certain set of goals, lexis, and genres in order to collaborate and succeed as a team. This parliamentary debate team's goal was to win as many rounds as possible in our extremely challenging tournaments across California. We practiced every Tuesday and Thursday for hours as we studied all the politics, current events, and history we needed to succeed. We expanded our minds and practiced speaking what we learned in order to argue it. While a difficult task, we continued practicing in order to achieve perfection and satisfaction.

To community most effectively when it came to terms and language, our discourse community formed lexis, or jargon when speaking. In debate rounds at tournaments, lexis, such as "motion", "point of order", and "resolution" are used in certain cases with meanings that only pertain to 
parliamentary debate. Using terminology that only the people in the discourse community understood made us feel more connected as members and gave us a stronger intercommunication system as a team.

A huge part of the parliamentary debate team was research, which led to the genre aspect of our discourse community. In the terms of discourse communities, genre refers the form in which the discourse is written such as graffiti, chalk drawings, magazine and newspaper articles, journals, websites, blogs, and other. As a community, we collaboratively researched to find information about the events that we needed to know about in order to feel the most prepared to succeed. These researches were located in a file drive that could be accessed by anyone within the discourse community. These genres we created proved the participatory mechanisms of the members and still shows the collaborative effort that a discourse community required.

Authors and writers tend to ask discourse community to full believe in the facts that are presented in order for readers to interpret the piece of writing as the writer intended them to. A better way to understand this concept is through Swale's article which says that "the author asks the discourse community to accept that the research about to be reported is part of a lively, significant, or well-established research area" (Swales 21). This makes the writing flow better as it is being read by the discourse community as they are not questioning the writing's credibility.

In my own writing, I tend to change the syntax and rhetoric based on the specific discourse community. When writing an essay for a class, I tend to write in a traditional, educational style as I know that a teacher will be reading the work. When writing a speech or an essay that I have to read aloud in front of a crowd, I write based on how it will sound so I can get the attention of who will be listening. I also tend to use tactics to capture the audience's attention like anecdotes or humor. 


\section{Appendix Fifteen: Case Study Gamma Draft Three}

\section{Discourse Communities}

While people who write tend to focus on things such as plot structure, rhetoric, and syntax, they often forget to think about discourse communities which is important when thinking about what kind of people will be reading a specific piece of writing. Discourse communities are groups of people that share a common interest, topics, or specific knowledge. This often connects them through similar vocabulary, linguistics, and jargon that is only understood by them. Discourse communities often have a common set of goals that members aim for in order to advance. This goal is helped to develop through lexis to contribute to intercommunication through their unique jargon and genres to articulate how the discourse community gets things done and operates through the linguistics.

It is a known argument that using a "discourse community entails assumptions about conformity and convention" meaning that in writing, it brings the audience and readers a sense of security and it hooks them. This argues that readers should keep discourse communities in mind to subconsciously coerce the reader to want to continue reading or listening to what the writer has to say because they seem connected to the topic and is guarantees that they are genuinely interested in it.

An example of a discourse community that I have been a part of is my high school's parliamentary debate team. The parliamentary debate consisted of a group of students that shared similar values and ethics to work towards a common victory. This discourse community shared a certain set of goals, lexis, and genres in order to collaborate and succeed as a team. This 
parliamentary debate team's goal was to win as many rounds as possible in our extremely challenging tournaments across California. We practiced every Tuesday and Thursday for hours as we studied all the politics, current events, and history we needed to succeed. We expanded our minds and practiced speaking what we learned in order to argue it. While a difficult task, we continued practicing in order to achieve perfection and satisfaction.

To community most effectively when it came to terms and language, our discourse community formed lexis, or jargon when speaking. In debate rounds at tournaments, lexis, such as "motion", "point of order", and "resolution" are used in certain cases with meanings that only pertain to parliamentary debate. Using terminology that only the people in the discourse community understood made us feel more connected as members and gave us a stronger intercommunication system as a team.

A huge part of the parliamentary debate team was research, which led to the genre aspect of our discourse community. In the terms of discourse communities, genre refers the form in which the discourse is written such as graffiti, chalk drawings, magazine and newspaper articles, journals, websites, blogs, and other. As a community, we collaboratively researched to find information about the events that we needed to know about in order to feel the most prepared to succeed. These researches were located in a file drive that could be accessed by anyone within the discourse community. These genres we created proved the participatory mechanisms of the members and still shows the collaborative effort that a discourse community required.

All the arguments that debaters research and write are presented in their rounds to a judge to evaluate them and choose a winner. Part of writing for a particular discourse community is writing for that particular type of person to understand and react in specific way to what the 
writer or speaker is trying to get across. In this case, debaters use unique wording and syntax in order to persuade and convince the judge to choose them as the winner.

A counterargument to write content with regards to discourse communities is that not all audiences will understand what the writer's message is because it is "sufficiently explicit for others to be able to accept, modify or reject on the basis of the criteria proposed." Because discourse communities have specific goals, lexis, and genres that only pertain exclusively to them, other groups of people will not be able to comprehend or learn from the writing, If a reader does not know what the jargon for the discourse community means then they do not gain any benefit from reading a writing that contains their lexis. However, for the benefits that the discourse community gains from the writing can outweigh the cost that outsiders face when reading it.

Authors and writers tend to ask discourse community to full believe in the facts that are presented in order for readers to interpret the piece of writing as the writer intended them to. A better way to understand this concept is through Swale's article which says that "the author asks the discourse community to accept that the research about to be reported is part of a lively, significant, or well-established research area" (Swales 21). This makes the writing flow better as it is being read by the discourse community as they are not questioning the writing's credibility.

In my own writing, I tend to change the syntax and rhetoric based on the specific discourse community. When writing an essay for a class, I tend to write in a traditional, educational style as I know that a teacher will be reading the work. When writing a speech or an essay that I have to read aloud in front of a crowd, I write based on how it will sound so I can get the attention of who will be listening. I also tend to use tactics to capture the audience's attention 
like anecdotes or humor. Using words that I know the audience will understand is beneficial because it connects me to the readers.

Discourse communities are important for writing because it gives a certain group of people the social perspective that they are craving. It makes the topic that is being written about even more relevant. Relating writing to a group's specific goals, lexis, and genres help make writing more relevant and it connects the audience on a new level.

https://pdfs.semanticscholar.org/778e/5c87e6041903980d25449c9a2972947a351e.pdf 


\section{Appendix Sixteen: Case Study Delta Draft One}

Expansion Essay Draft \#1

Topic: Process

- Hook/ intro

- Argument

- Each writer creates unique text with crucial skills that include utilizing resources, knowing multiple languages, and having flexible rules.

- $\quad$ Body Paragraph 1

- All writers create good text by using resources. In "Coordinating Constant Invention" by Stacey Pigg, she discusses how technology facilitates a person's writing process (Pigg). Specifically, social media facilitates activities and daily habits that are important to invention (Pigg). For example, websites with premade formats help individuals create their own profiles with ease. LinkedIn is a website that helps users create online profiles and resumes. LinkedIn makes it easy for the writer to create his or her own resume because it already has a premade outline with different categories that the writer just needs to fill out. This is much easier and less time consuming than writing a resume from scratch.

- Body Paragraph 2

On the other hand, writers may have difficulty writing when they use too many resources. Although websites with formats facilitate the writer's process of creating a profile, strict formats are detrimental to writers that experience writers block (Rose). When writers try to stick to a rigid format, it is difficult to come up 
with sentences that fit into the layout perfectly, so writer's just stop writing when their words cannot fit properly. In this case, writers should abandon their previous habits of following the rigid writing rules and be more flexible. This will allow them to get more words on a page.

\section{- $\quad$ My Process 1}

- In the in-class activity, I started my process by writing full sentences on my paper because I had a limited amount of time. I wrote chronologically, and divided my paragraphs into an introduction, two body paragraphs, and a conclusion. I did have some structure to my piece, but I would make a stronger thesis and lengthen my introduction and conclusion paragraphs if I had more time. The activity in class showed me that I am a more organized writer than I thought. I always assumed it was normal to make and outline before writing, but when discussing with my group, I found out that I am the only one who does.

- Discuss my usual process when I have days (outline)

- $\quad$ My Process 2

- My group and I formed our argument based which side we had more evidence for/ which side was easiest to write about with our research (we didn't agree with our argument)

- Conclusion 


\section{Appendix Seventeen: Case Study Delta Draft Two}

\section{Expansion Essay Draft 2}

When an individual hears of the word "process", he or she thinks of a set of directions or steps on how to complete a task. Those individuals assume process is referring to one set of instructions that everybody can follow. When it comes to writing, everybody's process is more complicated than a general layout on what to do. Each person has his or her own way of creating text. Each sophisticated, experienced writer creates unique text by using crucial skills including utilizing resources, being okay with errors, and having flexible rules.

To begin with, all writers create good text by using resources. In "Coordinating Constant Invention" by Stacey Pigg, she discusses how technology facilitates a person's writing process (Pigg, 713). Specifically, social media facilitates activities and daily habits that are important to invention (Pigg, 713). For example, websites with pre-made formats help individuals create their own profiles with ease. LinkedIn is a website that helps users create online profiles and resumes. This website makes it easy for the writers to create their own resumes because it already has a pre-made outline with different categories that the writer just needs to fill out. This is much easier and less time consuming than writing a resume from scratch, especially for people who have never made a resume before. For example, when I applied for on-campus jobs earlier this year, I utilized LinkedIn to figure out how to organize my resume into categories, such as community service, professional experience, etc.

Also, I use Google Docs to facilitate my writing process. The automatic save feature helps me because I do not need to remember to constantly save my work and can spend more 
time writing. Likewise, the comment feature lets me highlight parts of my document and leave a comment in the margins about something I want to edit later.

Specifically, Google Docs also facilitates group projects, for each person has access to the same document from his or her own platform and everybody can edit it simultaneously. For example, my group always uses Google Docs in my first year foundations course, so we can each add to the document whenever it is convenient for us. We do not need to meet up in person to work on the project; we just need to type our part, and everybody can see it from his or her computer. This saves time and energy that would be otherwise used if we had to meet up to work on the project, each write our parts down, and copy everybody else's parts.

Moreover, when discussing my writing process with my small group as an in-class activity, I quickly learned that my process is different from most people. I start my process by brainstorming my main topic for a few days before I start to write anything. Once I decide on my argument, I begin to create an outline. First, I write a strong thesis statement, making sure that it answers the prompt and is a topic that allows for a lot of analysis. Then, I plan the topics of my body paragraphs and find concrete detail or quotes to expand my argument. Next, I transform my outline into complete sentences. This step is the hardest part for me because I need to make sure that my meaning does not get lost in translation; however, the outline makes it easier to get words on a page because I had already brainstormed about what I want to write about. Once I have all of my thoughts into full sentences and paragraphs, I add transition words and phrases to make my essay flow better. Also, I edit my word choice and grammar, and just do any final edits before turning it in.

Although I prefer making an outline before I start to write, my process changes when I am faced with a time limit, like the activity in class. I tend to make an outline if I have at least a 
few days to complete the assignment, but I did not make an outline for the activity in class because I only had 15 minutes. In this case, I started my process by writing full sentences on my paper. I wrote chronologically, dividing my paragraphs into an introduction, two body paragraphs, and a conclusion. I did have some structure to my piece, but I would make a stronger thesis and lengthen my introduction and conclusion paragraphs if I had more time.

The in-class activity showed me that I am a more organized writer than I thought. I always assumed it was normal to make and outline before writing a long piece, but when discussing with my group, I found out that I am the only one who does.

Although I have an organized routine on how I write a paper, I do not do everything in one sitting. When I write for too long, my brain starts to slow down, and it is difficult for me to continue writing. Specifically, I have trouble continuing to write when I do not know how to transform my thoughts into words on paper. Writers who have a strict format about how their essays should be written are prone to this phenomena of "writer's block" (Rose, 791). To cope with writer's block, I take frequent breaks when I am writing; however, I strategically schedule my breaks. I cannot take a break when I am in the "zone" and am focusing really hard, but it does help me to take a break after I get a few paragraphs done, so I can relax and refresh my brain.

After my essay is fully written, I revise it and read it over and over until it sounds just how I want. Throughout middle school and high school, I used to focus mainly on grammar when editing pieces because that is what the teachers thought was important. Teachers graded my essays as if grammar was the only component. As I mentioned in my first blog post, each teacher has his or her own concept of a good paper, so it makes me self conscious to turn in my work, in fear of getting a bad grade. When I see red marks all over my paper for grammar edits, 
it makes me feel like my writing is not good enough. I have always struggled to understand how teachers can accurately grade writing because I view it as a form of art without one correct way to do it.

Furthermore, after reading Williams' "Phenomenology of Error", I now realize that grammatical errors, or errors in general, do not make or break a paper. Error is a construct, meaning everybody makes errors (Williams, 804). Nobody can escape it. It is just part of everybody's writing process. That is what makes revision so important; it helps fix those errors. Now when I look at my papers, I do not feel so embarrassed about my little mistakes, but I am proud of the components I do well, like my strong arguments and critical thinking.

Ultimately, Writing About Writing has helped me realize my own writing process. Although I used to be self conscious about my writing, taking pride in my process and in my work has helped me gain confidence. By utilizing resources, being okay with errors, and having flexible rules, I am able to write to my best ability.

\section{Works Cited}

Pigg, Stacey. “Coordinating Constant Invention: Social Media’s Role in Distributed Work.” Technical Communication Quarterly, vol. 23, no. 2, March 2014, pp. 69-87.

Rose, Mike. "Rigid Rules, Inflexible lans, and the Stifling of Language: A Cognitivist Analysis of Writer's Block." College Composition and Communication, vol. 31, no. 4, Dec. 1980, pp. 389-401.

Williams, Joseph M. “The Phenomenology of Error.” College Composition and Communication, vol. 32, no. 2, May 1981, pp. 152-68 


\section{Appendix Eighteen: Case Study Delta Draft Three}

\section{Expansion Essay Draft 3}

When an individual hears of the word "process", he or she thinks of a set of directions or steps on how to complete a task. Those individuals assume process is referring to one set of instructions that everybody can follow. When it comes to writing, everybody's process is more complicated than a general layout on what to do. Each person has his or her own way of creating text. Each sophisticated, experienced writer creates unique text by using crucial skills including utilizing resources, being okay with errors, and having flexible rules.

To begin with, all writers create good text by using resources. In "Coordinating Constant Invention” by Stacey Pigg, she discusses how technology facilitates a person's writing process (Pigg, 713). Specifically, social media facilitates activities and daily habits that are important to invention (Pigg, 713). For example, websites with pre-made formats help individuals create their own profiles with ease. LinkedIn is a website that helps users create online profiles and resumes. This website makes it easy for the writers to create their own resumes because it already has a pre-made outline with different categories that the writer just needs to fill out. This is much easier and less time consuming than writing a resume from scratch, especially for people who have never made a resume before. For example, when I applied for on-campus jobs earlier this year, I utilized LinkedIn to figure out how to organize my resume into categories, such as community service, professional experience, etc.

Also, I use Google Docs to facilitate my writing process. The automatic save feature helps me because I do not need to remember to constantly save my work and can spend more 
time writing. Likewise, the comment feature lets me highlight parts of my document and leave a comment in the margins about something I want to edit later.

Specifically, Google Docs also facilitates group projects, for each person has access to the same document from his or her own platform and everybody can edit it simultaneously. For example, my group always uses Google Docs in my first-year foundations course, so we can each add to the document whenever it is convenient for us. We do not need to meet up in person to work on the project; we just need to type our part, and everybody can see it from his or her computer. This saves time and energy that would be otherwise used if we had to meet up to work on the project, each write our parts down, and copy everybody else's parts.

Moreover, when discussing my writing process with my small group as an in-class activity, I quickly learned that my process is different from most people. I start my process by brainstorming my main topic for a few days before I start to write anything. Once I decide on my argument, I begin to create an outline. First, I write a strong thesis statement, making sure that it answers the prompt and is a topic that allows for a lot of analysis. Then, I plan the topics of my body paragraphs and find concrete detail or quotes to expand my argument. Next, I transform my outline into complete sentences. This step is the hardest part for me because I need to make sure that my meaning does not get lost in translation; however, the outline makes it easier to get words on a page because I had already brainstormed about what I want to write about. Once I have all of my thoughts into full sentences and paragraphs, I add transition words and phrases to make my essay flow better. Also, I edit my word choice and grammar, and just do any final edits before turning it in.

Although I prefer making an outline before I start to write, my process changes when I am faced with a time limit, like the activity in class. I tend to make an outline if I have at least a 
few days to complete the assignment, but I did not make an outline for the activity in class because I only had 15 minutes. In this case, I started my process by writing full sentences on my paper. I wrote chronologically, dividing my paragraphs into an introduction, two body paragraphs, and a conclusion. I did have some structure to my piece, but I would make a stronger thesis and lengthen my introduction and conclusion paragraphs if I had more time.

The in-class activity showed me that I am a more organized writer than I thought. I always assumed it was normal to make and outline before writing a long piece, but when discussing with my group, I found out that I am the only one who does.

Although I have an organized routine on how I write a paper, I do not do everything in one sitting. When I write for too long, my brain starts to slow down, and it is difficult for me to continue writing. Specifically, I have trouble continuing to write when I do not know how to transform my thoughts into words on paper. Writers who have a strict format about how their essays should be written are prone to this phenomena of "writer's block" (Rose, 791). To cope with writer's block, I take frequent breaks when I am writing; however, I strategically schedule my breaks. I cannot take a break when I am in the "zone" and am focusing really hard, but it does help me to take a break after I get a few paragraphs done, so I can relax and refresh my brain.

After my essay is fully written, I revise it and read it over and over until it sounds just how I want. Throughout middle school and high school, I used to focus mainly on grammar when editing pieces because that is what the teachers thought was important. Teachers graded my essays as if grammar was the only component. As I mentioned in my first blog post, each teacher has his or her own concept of a good paper, so it makes me self-conscious to turn in my work, in fear of getting a bad grade. When I see red marks all over my paper for grammar edits, 
it makes me feel like my writing is not good enough. I have always struggled to understand how teachers can accurately grade writing because I view it as a form of art without one correct way to do it.

Furthermore, after reading Williams' "Phenomenology of Error", I now realize that grammatical errors, or errors in general, do not make or break a paper. Error is a construct, meaning everybody makes errors (Williams, 804). Nobody can escape it. It is just part of everybody's writing process. That is what makes revision so important; it helps fix those errors. Now when I look at my papers, I do not feel so embarrassed about my little mistakes, but I am proud of the components I do well, like my strong arguments and critical thinking.

Ultimately, Writing About Writing has helped me realize my own writing process. Although I used to be self-conscious about my writing, taking pride in my process and in my work has helped me gain confidence. By utilizing resources, being okay with errors, and having flexible rules, I am able to write to my best ability.

\section{Works Cited}

Pigg, Stacey. "Coordinating Constant Invention: Social Media's Role in Distributed Work." Technical Communication Quarterly, vol. 23, no. 2, March 2014, pp. 69-87. 
Rose, Mike. "Rigid Rules, Inflexible Plans, and the Stifling of Language: A Cognitivist Analysis of Writer's Block." College Composition and Communication, vol. 31, no. 4, Dec. 1980, pp. 389-401.

Williams, Joseph M. “The Phenomenology of Error.” College Composition and Communication, vol. 32, no. 2, May 1981, pp. 152-68. 